ISSN: 0514-7336

DOI: http://dx.doi.org/10.14201/zephyrus201780147172

\title{
CONTEXTOS CERÁMICOS TARDOANTIGUOS PROCEDENTES DEL EDIFICIO PALACIAL DE SANTA MARÍA DE ABAJO DE CARRANQUE (TOLEDO)
}

\section{Late Antiquity ceramic contexts from the Palatial Building of Santa Maria de Abajo of Carranque (Toledo)}

\author{
Virginia García Entero*, Yolanda Peña Cervantes*, Eva Zarco Martínez** y Raúl Aranda González*** \\ * Dpto. de Prehistoria y Arqueología. Facultad de Geografía e Historia-UnED. C/ Senda del Rey, 7. 28040 Madrid. \\ Correo-e:vgarciaentero@geo.uned.es; yolandapcervantes@geo.uned.es \\ ** Equipo de Investigación de Carranque. Correo-e: eva.zarco.m@gmail.com \\ *** Instituto Catalán de Arqueología Clásica (ICAC). Plaça d'en Rovellat, s/n. 43003 Tarragona. Correo-e: raranda@icac.cat
}

Recepción: 17/09/2016; Revisión: 20/02/2017; Aceptación: 3/07/2017

\begin{abstract}
Resumen: Los trabajos de excavación arqueológica desarrollados en el yacimiento de Santa María de Abajo (Carranque, Toledo) entre 2009 y 2011, centrados en el espacio ocupado por el palacio tardorromano, han permitido conocer una larga secuencia ocupacional desarrollada entre época romana y los primeros años del s. xx. En este trabajo presentamos el estudio de diez contextos cerámicos asociados a los niveles tardoantiguos localizados en estas excavaciones, contextos que han permitido identificar nueve grupos cerámicos, cuyas características presentamos, y caracterizar, a partir de la secuencia estratigráfica asociada, la ocupación tardoantigua -desde mediados del s. v a finales del viI. d. C.- instalada sobre el antiguo edificio palacial de Carranque. El estudio realizado ha permitido comenzar a caracterizar los ritmos de esta ocupación tardoantigua en el solar analizado e identificar tres momentos: los dos primeros coinciden con estructuras de hábitat -Fase $2-$ y el tercero se asocia a una necrópolis -Fase 3-.

Palabras clave: cerámica tardoantigua; necrópolis visigoda; hábitat tardoantiguo; Península Ibérica.
\end{abstract}

AвStRact: The archaeological excavation works developed at the site of Santa María de Abajo (Carranque, Toledo) between 2009 and 2011, focused on the space occupied by the Late Roman Palace, have allowed us to know a long occupational sequence developed between Roman times and the early years of 20th century. In this work we present the study of ten ceramic contexts associated with Late Antiquity levels. These contexts allow to identify nine ceramic groups and to know the Late Antiquity sequence -middle $5^{\text {th }}$ to the end of $7^{\text {th }}$ century $\mathrm{AD}-$ in this area of the site of Carranque. The performed study allows us to begin to characterize the moments of this Late Antiquity occupation in the analyzed space, being identified three moments; the two first coincide with habitat structures -Phase 2- and the third one is associated to a necropolis -Phase 3-.

Key words: Late Antiquity pottery; Late Roman necropolis; Late Antiquity habitat; Iberian Peninsula.

\section{Introducción}

El yacimiento arqueológico de Santa María de Abajo se encuentra situado en el término municipal de Carranque (Toledo), de cuyo centro urbano dista $5 \mathrm{~km}$ (Fig. 1). El yacimiento, que ocupa una extensión de 18 ha, está enclavado en una terraza fluvial en la margen derecha del río Guadarrama en la 


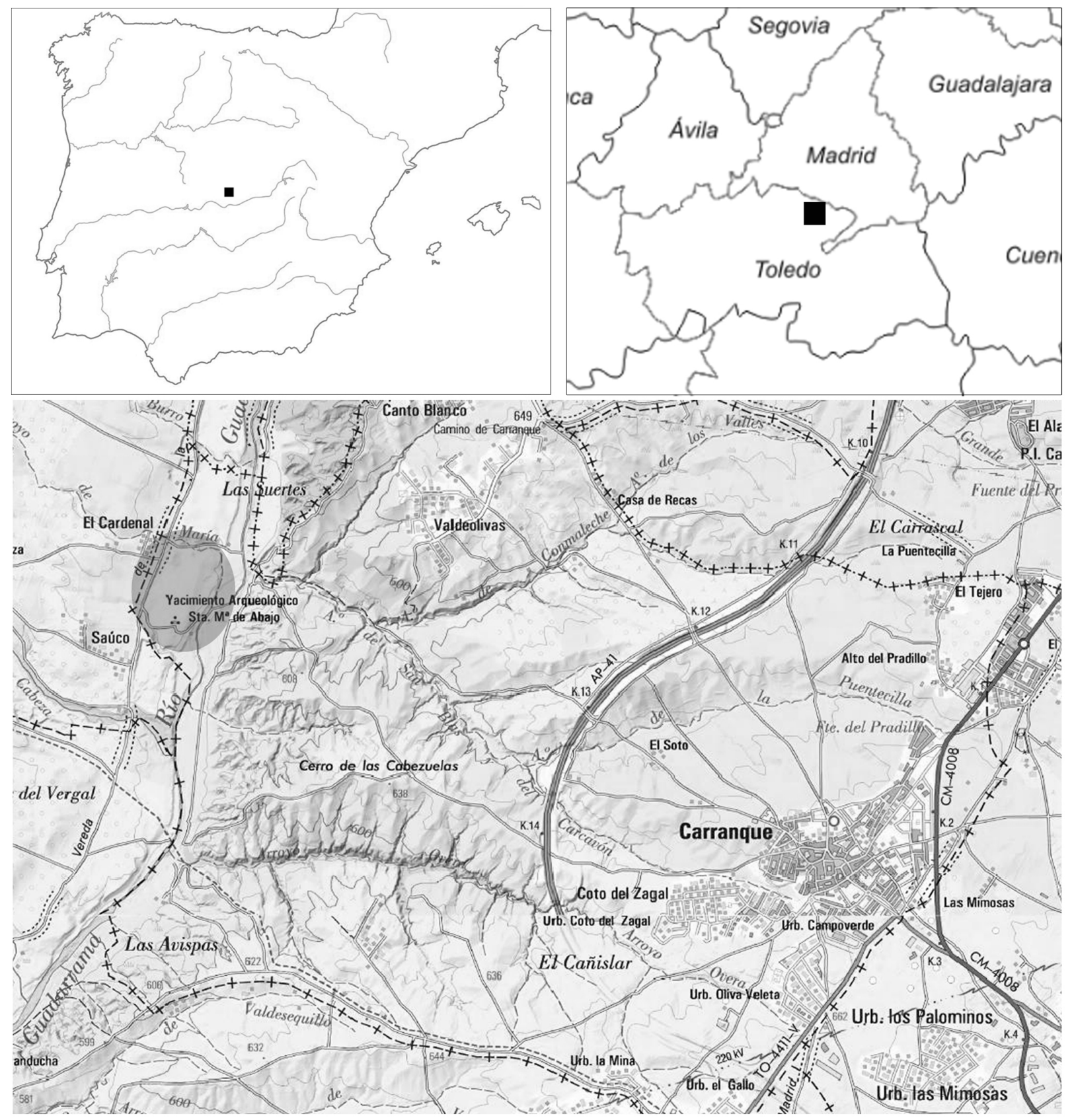

Fig. 1. Localización del yacimiento de Carranque (Toledo).

que se distribuyen edificios y estructuras exhumadas a lo largo de tres décadas desde el descubrimiento fortuito del yacimiento en 1983 (Fig. 2). La investigación arqueológica ${ }^{1}$ que venimos desarrollando

1 Este trabajo se inscribe en el marco de los proyectos de investigación Estudio del material arqueológico procedente desde 2004 se ha centrado principalmente en la resolución de cuestiones interpretativas sobre los

de las campañas 2009-2011. Yacimiento arqueológico de Carranque (Toledo) 2014, dirigido por C. Fernández Ochoa y V. García-Entero, y Proyecto de investigación en el yacimiento de Carranque (Toledo) 2015, dirigido por C. Fernández 


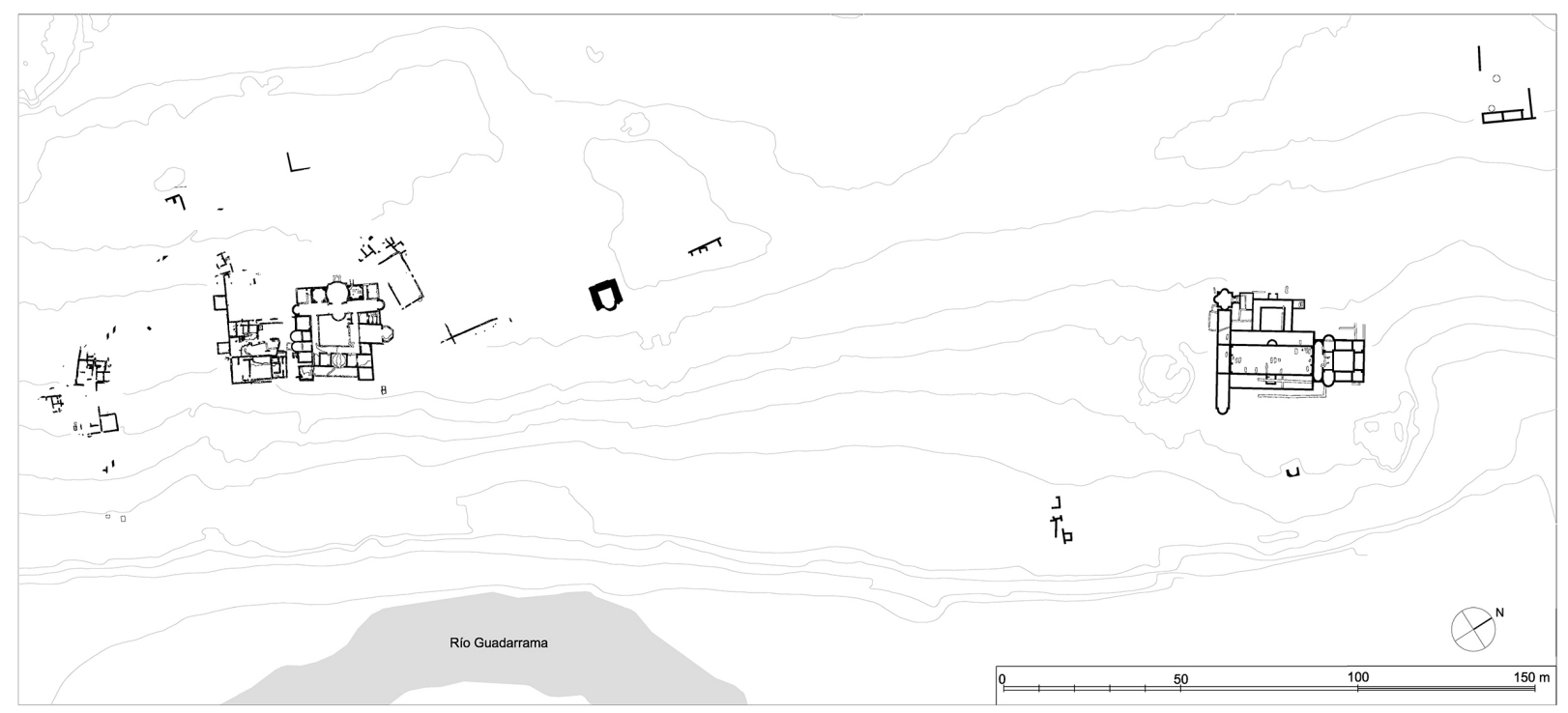

FIG. 2. Planta general del yacimiento de Carranque (Toledo).

edificios excavados entre 1985 y 2003 y en la obtención de una secuencia estratigráfica a partir de la excavación selectiva de sectores concretos del yacimiento que ya habían sido intervenidos por el equipo anterior ${ }^{2}$. En este marco se encuadran las intervenciones desarrolladas entre 2009 y 2011 en el espacio del palacio tardorromano que se sitúa en el extremo norte del yacimiento. Estos trabajos nos han permitido conocer una larga secuencia en la que hemos identificado nueve fases (Fig. 3) que abarcan una ocupación iniciada en época romana y que culmina en los primeros años del s. xx con la destrucción de la parte del edificio tardorromano que aún se mantenía en pie (García-Entero et al.,

Ochoa, V. García-Entero, Y. Peña Cervantes y E. Zarco Martínez, subvencionados por la Dirección General de Cultura de la Consejería de Educación, Cultura y Deportes de la Junta de Comunidades de Castilla-La Mancha en las convocatorias de 2014 y 2015, respectivamente, y cofinanciados por la Facultad de Geografía e Historia de la UNED. El trabajo se enmarca, asimismo, en las actividades del proyecto de I + D + I del Plan Nacional de Investigación Marmora Hispaniae. Explotación, uso y difusión de la caliza de Espejón en la Hispania romana y tardoantigua (HAR 2013-44971-P) dirigido por V. García-Entero, y del Grupo de Investigación consolidado de la UNED 454 Paisajes, arquitecturas y cultura material en la Iberia antigua.

2 Cf. Fernández Ochoa et al., 2012 y García-Entero et al., 2014 con la bibliografía de referencia.
2014 y 2017$)^{3}$. En las páginas que siguen presentamos el estudio del material cerámico procedente de los contextos tardoantiguos localizados en las intervenciones arqueológicas llevadas a cabo entre 2009 y 2011 en el espacio ocupado por el edificio palacial tardorromano.

\section{La secuencia ocupacional}

De manera muy sintética, y antes de abordar el análisis cerámico objeto de este estudio, queremos exponer brevemente la secuencia de ocupación (Fig. 3) identificada en el solar ocupado por el palacio tardorromano, haciendo hincapié en el hecho de que el avance en el estudio ahora presentado -frente a un trabajo preliminar previo (García-Entero et al., 2014) - nos ha permitido matizar algunas cuestiones relativas a los horizontes tardoantiguo -objeto de este trabajo- y emiral (García-Entero et al., 2017). No podemos dejar de apuntar que nuestras intervenciones de 2009 a 2011 se realizaron en un sector

3 García-Entero, V.; Peña, Y.; Zarco, E.; Elvira, A. y Vidal, S.: "La necrópolis de época visigoda de Santa María de Abajo (Carranque, Toledo)". En La Meseta Sur entre la Tardia Antigüedad y la Alta Edad Media. Reunión Cientifica (Almadén, 2015). Toledo, en prensa. 
que había sido objeto de una intensa actuación arqueológica previa entre 1988 y 2003, de tal manera que la planta completa del edificio palacial tardorromano estaba ya completamente exhumada y prácticamente desaparecidos los niveles de ocupación no sólo de la época tardorromana, sino también de las fases posteriores. La secuencia ocupacional que se indica a continuación es fruto de la realización de intervenciones puntuales llevadas a cabo en estratos no excavados con anterioridad y que aún conservaban información cronoestratigráfica válida, aunque en la mayoría de los casos las unidades intervenidas se encontraban aisladas, desde el punto de vista estratigráfico, por la excavación precedente ${ }^{4}$.

- Fase 0: hemos documentado una primera fase constructiva identificada únicamente en el costado occidental del edificio palacial y a la que se asocian dos cimentaciones murarias, una zanja y niveles de frecuentación que han aportado escasos materiales cerámicos de cronología altoimperial. Estas estructuras resultaron amortizadas en la Fase $1 \mathrm{~b}$ por la construcción del cuerpo occidental ańadido a la planta original del edificio palacial.

- Fase 1: en la terraza más próxima al río Guadarrama y en el sector norte del yacimiento se levantó un gran edificio civil de representación, de más de $2000 \mathrm{~m}^{2}$, diseńado con un eje axial $\mathrm{N}-\mathrm{S}$ y levantado sobre una potente cimentación de opus caementicium. La construcción ahora erigida es un gran edificio de representación en el que, siguiendo modelos arquitectónicos propios de la arquitectura palatina definida a partir

4 Este sector del yacimiento en el que se encuentra el edificio palacial tardorromano -identificado por sus primeros excavadores como basílica cristiana- fue excavado durante los años 1988, 1989, 1992 y 1995 a 2003 bajo la dirección de D. Fernández Galiano y B. Patón Lorca, quedando exhumada una superficie de $c .4000 \mathrm{~m}^{2}$ en la que se rebajó una potencia sedimentaria de $c$. de $1,5 \mathrm{~m}$. La documentación disponible sobre esta intervención es escasa y adolece de la ausencia de metodología estratigráfica durante el proceso de exhumación, lo que ha dificultado el estudio que hemos realizado condicionando la selección de unidades estratigráficas -UUEE en adelante- sobre las que hemos intervenido arqueológicamente. de época tetrárquica, la mayor parte de los espacios están concebidos para dar cobijo a toda una serie de ceremonias encaminadas a poner de manifiesto el poder y estatus del propietario del complejo5. En función de los datos estratigráficos disponibles, carecemos de materiales que nos permitan determinar la fecha de construcción del complejo palacial, que sabemos que perdió su función original en torno a mediados del s. v d. C. El estudio realizado sobre las estructuras murarias nos ha permitido identificar dos momentos constructivos que pertenecen a una misma planificación edilicia. En la fase designada como 1a, se engloba la construcción del cuerpo central del edificio palacial, quedando marcados los muros de conexión con el ala occidental. En la llamada fase 1 b, se construyó el cuerpo occidental del edificio palacial que presenta, como única diferencia constructiva respecto a la fase 1a, la ausencia de sillares de granito que sirven de asiento al alzado de mampostería y ladrillo del resto del edificio.

- Fase 2: ocupación habitacional tardoantigua del edificio palacial. Las actuaciones adscribibles a esta fase afectaron principalmente al sector occidental del complejo, si bien hay que destacar que los límites impuestos por la excavación y puesta en valor del palacio tardorromano impiden conocer la extensión de la ocupación de este momento. Detectamos la presencia de una serie de estructuras negativas junto con dos elementos de combustión concentrados en la mitad occidental del espacio. También hemos identificado la creación de una estancia cuadrangular en el exterior oriental del conjunto palacial para cuya

$5 C f$., entre otros, los ya clásicos estudios de Lavin, 1962; Matthews, 1975, o Ellis, 1984 y 1991, a los que cabe sumar Balmelle, 2001; Baldini Lippolis, 2002; Sfameni, 2006; Chavarría et al., 2006; Mar y Verde, 2008, y Wilson, 2011; asimismo Pensabene y Sfameni, 2014. Sobre la polémica vinculación del complejo de Carranque con el círculo de poder teodosiano propuesta por D. Fernández-Galiano y fuertemente rebatida, remitimos a la bibliografía citada en la nota 6. La decoración marmórea de este edificio ha sido objeto de especial atención en los últimos años. Véanse principalmente García-Entero y Vidal, 2007 y 2012. 


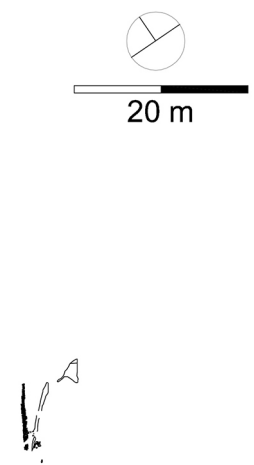

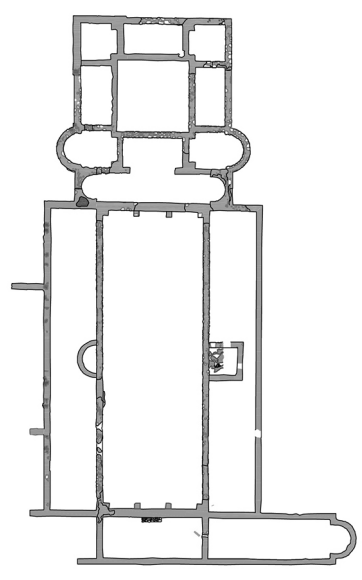

FASE 1A

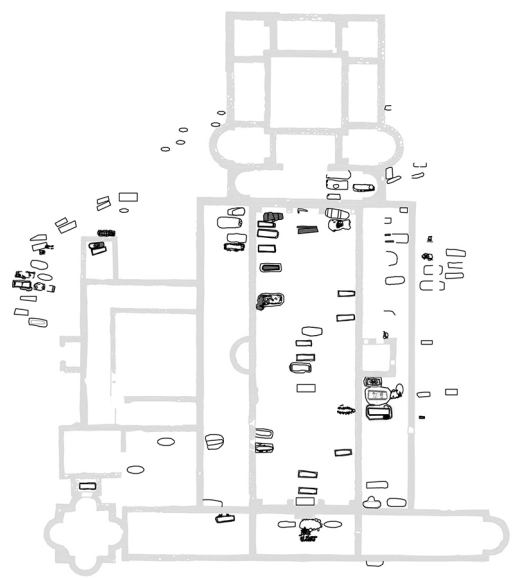

FASE 3

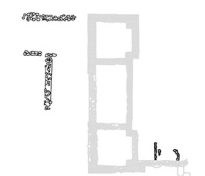

1

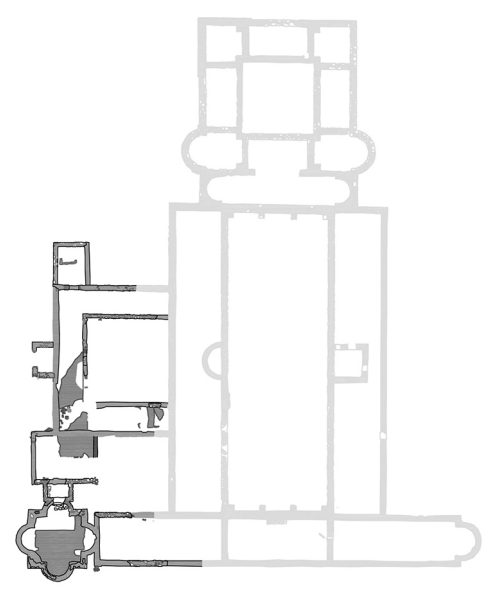

FASE 1B

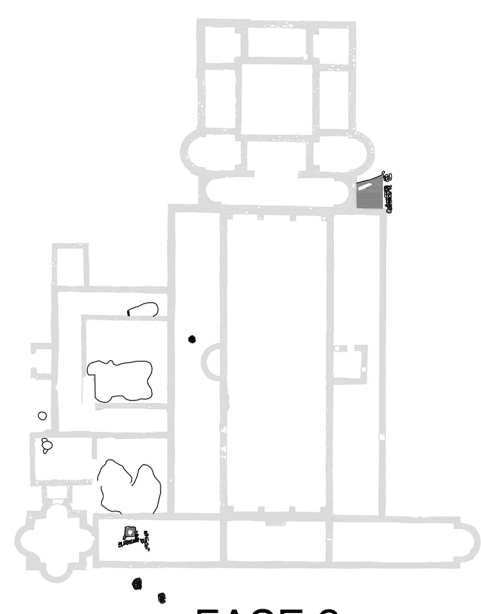

FASE 2

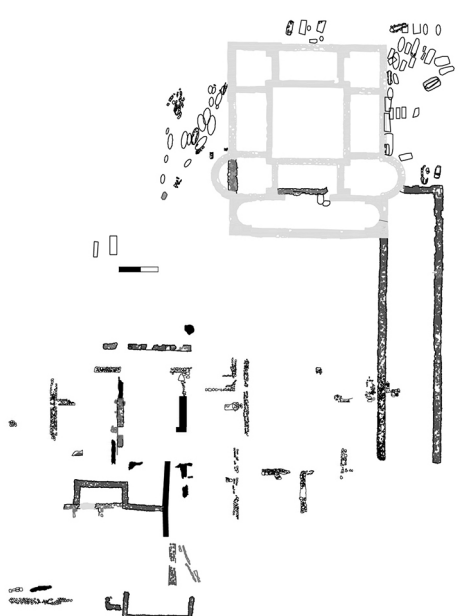

FASE 6
FASE 7

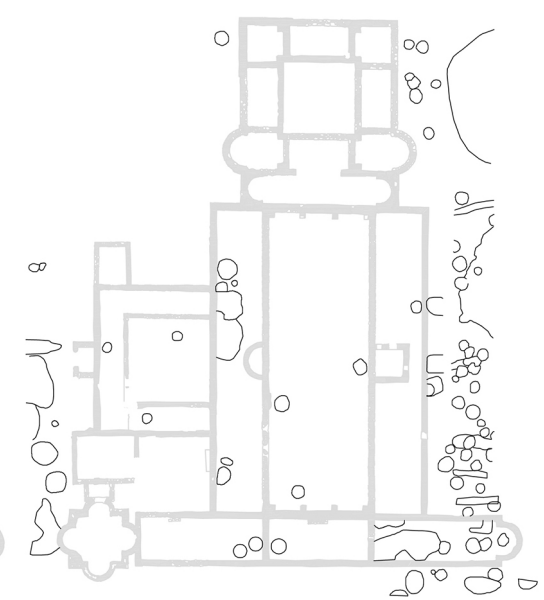

FASE 4

F)

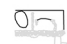

FIG. 3. Fases de ocupación detectadas en el yacimiento de Carranque (Toledo). 
construcción se reaprovechó parte de los muros de la fachada del complejo a los que se sumaron dos potentes tramos murarios en los que ya se evidencia la reutilización de material constructivo de parte del edificio palacial. La nueva sala, de $12 \mathrm{~m}^{2}$, fue pavimentada por un suelo de opus signinum de gran calidad que aparece cortado por inhumaciones de la necrópolis de época visigoda (Fase 3). Esta misma secuencia la hemos detectado en el relleno de alguna de las fosas de esta fase que aparecen cortados por tumbas de esta necrópolis.

- Fase 3: la necrópolis de época visigoda. En este momento asistimos a la clara transformación funcional del espacio que asume ahora una función funeraria con la instalación de una amplia necrópolis formada por más de un centenar de tumbas (García-Entero y Vidal, 2012) ${ }^{6}$. La necrópolis parece surgir en torno a un edificio de culto cristiano a cuya decoración arquitectónica es posible vincular toda una serie de elementos escultóricos entre los que se encuentran placas de cancel, cimacios, molduras y fragmentos de capitel, todos ellos datables en el s. viI d. C. y obrados en caliza en un taller toledano. No obstante, por el momento desconocemos el lugar en el que se instaló dicha iglesia, que bien pudo estar ubicada, o bien fuera del espacio excavado, o bien construida sobre la ruina del edificio palacial tardorromano, fue desmantelada por las ocupaciones sucesivas posteriores ${ }^{7}$.

- Fase 4: ocupación emiral. En época emiral se produjo una intensa ocupación del solar del antiguo edificio palacial tardorromano y del área inmediatamente circundante. A esta fase es posible asociar varias decenas de estructuras de almacenaje en silos, diversas fosas de extracción de gran tamaño identificadas especialmente en el costado oriental del edificio palacial, y un pozo de más de $3 \mathrm{~m}$ de profundidad que aprovechaba el agua del nivel

6 También cf. García-Entero et al., op. cit. n. 3.

7 Se trata de varias piezas y fragmentos de piezas documentados durante las intervenciones llevadas a cabo entre 1988 y 2003; este material escultórico está siendo estudiado por S. Vidal Álvarez. freático. El edificio palacial continuaba en buena medida aún en pie en este momento, como así pone de relieve la presencia de una inscripción realizada sobre uno de los fustes de columna del complejo tardorromano ${ }^{8}$. La necrópolis de época visigoda resultó amortizada en este momento, como demuestra la instalación de silos sobre algunas de las inhumaciones. El estudio de los materiales cerámicos emirales asociados a este horizonte ha sido abordado de manera monográfica en un trabajo reciente (García-Entero et al., 2017).

- Fase 5: abandono temporal de la ocupación. Durante un amplio período de tiempo que podemos situar cronológicamente entre un momento indeterminado del s. x y las primeras décadas del XII, el solar parece objeto de un abandono generalizado que arqueológicamente se manifiesta en la ruina parcial de las estructuras y en la ausencia de contextos fechables en esta cronología.

- Fase 6: la ocupación medieval cristiana con la iglesia y el monasterio de Santa María de Batres. A partir de este momento, para la reconstrucción histórica de lo ocurrido en el solar del antiguo edificio palacial de Carranque, a la documentación arqueológica se suma también la documentación textual, que permite identificar la creación de la iglesia de Santa María de Batres atestiguada desde, al menos, el año 1136, momento en el que el rey Alfonso VII dona el castillo de Calatalifa, entre cuyas tierras se halla la iglesia de Santa María de Batres, a la iglesia de Segovia. Arqueológicamente, esta iglesia podemos ubicarla en el sector norte del antiguo edificio palacial que en este momento se mantiene aún en pie. En torno a esta iglesia de Santa María de Batres surgió una necrópolis que se extendió alrededor de la cabecera del antiguo edificio, en su extremo norte. A estas evidencias arqueológicas de la fase 6 , cabe añadir una serie de estructuras murarias de gran solidez constructiva

8 A pesar de una primera interpretación de la inscripción como coránica (López Lancha, 2001), recientemente se ha propuesto una nueva lectura según la cual la inscripción aludiría a la propiedad de los materiales lapídeos del edificio palacial para su expolio en época andalusí (Rodríguez Morales y Viguera, 2014). 
que parecen configurar una amplia zona de habitación anexa al lugar de culto. La existencia del monasterio vinculado a la iglesia de Santa María de Batres, atestiguado en 1152, podría explicar la existencia de dichas estructuras de habitación.

- Fase 7: la ocupación de época moderna. Ermita rural de Santa María de Batres. En una fase posterior que podemos situar en época moderna, la necrópolis medieval resultó amortizada, como así evidencian una serie de estructuras erigidas al o y e de la iglesia de Santa María de Batres que, sin embargo, mantiene su función cultual, ahora como ermita rural, tal y como aparece relatado en las Relaciones Topográficas de Felipe II de $1576^{9}$ donde se hace referencia a una ermita junto al río Guadarrama de la que apenas se conserva una capilla de bóveda de piedra y ladrillo. Esta ermita estuvo en funcionamiento hasta mediados del s. XIX, momento el que, cesado ya el culto, comenzó su abandono y ruina.

- Fase 8: la ocupación marginal de época contemporánea. La última fase arqueológicamente identificada en el complejo ocupado por el antiguo edificio palacial tardorromano se corresponde con una ocupación contemporánea producida tras el abandono de la ermita que puede datarse a mediados del s. XIx. Con gran parte del edificio ya arruinado, al menos una de las habitaciones de la antigua ermita resultó cobijo para una serie de ocupaciones marginales de diversa índole.

\section{Metodología del estudio realizado}

En este trabajo presentamos el análisis pormenorizado del material cerámico de un conjunto de unidades estratigráficas seleccionadas atendiendo

9 “... Hay una ermita que se intitula Santa María de Batres, al Oriente una legua desta villa, junto al río de Guadarrama desta parte, donde no hay más que una capilla de bóveda de piedra y ladrillo, que es muy antigua, dícese haber sido monasterio y abadía de templarios y lo demás de la dicha iglesia esta puesto por el suelo, esta ermita tiene termino de algunas tierras que comienzan desta parte del dicho río y pasa de la otra parte, y esta anexado al monasterio de monjas de la villa de Griñón...” (Viñas Mey y Paz, 1951-1963: 237). a criterios estratigráficos y de representatividad del material asociado. Se trata del estudio de la cerámica asociada a diez contextos de época tardoantigua (Figs. 4 y 5), con un total de 929 fragmentos que se corresponden con un número mínimo de individuos de $76^{10}$. De esta forma, presentamos aquí el estudio de los materiales cerámicos pertenecientes a las Fases 2 y 3 de edificio palacial, que se corresponden respectivamente, como hemos visto, con un momento de ocupación habitacional y con una fase de necrópolis.

Así, estudiamos aquí los materiales cerámicos vinculados a los rellenos UUEE 10317, 10205, $10319 / 10321$ y 10324 correspondientes a fosas localizadas en el ala occidental del edificio palacial. Asimismo, hemos estudiado los rellenos de las UUEE 10740 y 10784 correspondientes a silos localizados en el mismo sector. Asociados a este mismo horizonte hemos analizado los materiales de las UUEE 10312 y 10658 correspondientes a niveles de uso vinculados a estructuras de combustión. Todas estas unidades se vinculan con la Fase 2 del edificio palacial. Incluimos también en el estudio el análisis del relleno de la UE 10288 perteneciente a la tumba 154 y el ajuar cerámico - UE 10226- de la tumba 1 , ambas unidades asociadas a la necrópolis de época visigoda (Fase 3 ) instalada en este espacio ${ }^{11}$.

Hemos detectado la presencia de siete grupos tecnológicos cerámicos pertenecientes al horizonte de ocupación tardoantigua, algunos de ellos de clara tradición tardorromana y ya identificados con anterioridad en otras zonas del yacimiento ${ }^{12}$. Nos

10 Para esta cifra se han contabilizado exclusivamente los bordes. El estudio ahora presentado se ha realizado de forma conjunta con los materiales cerámicos asociados a la fase emiral del yacimiento. Buena parte del material cerámico de los rellenos estudiados no presentan rasgos morfológicos que nos permitan determinar con certeza su pertenencia a un horizonte tardoantiguo o emiral. Por motivos de espacio presentamos aquí únicamente los contextos cerámicos tardoantiguos; los contextos emirales han sido publicados en García-Entero et al., 2017.

11 Cf. García-Entero et al., op. cit. n. 3.

12 Fernández Ochoa, C.; García-Entero, V.; Peña, Y.; Zarco, E. y Elvira, A. (2013): El complejo productivo de la villa romana de Carranque (Toledo). Memoria inédita depositada en la Consejería de Educación, Cultura y Deportes de la junta de Comunidades de Castilla-La Mancha, Toledo. 


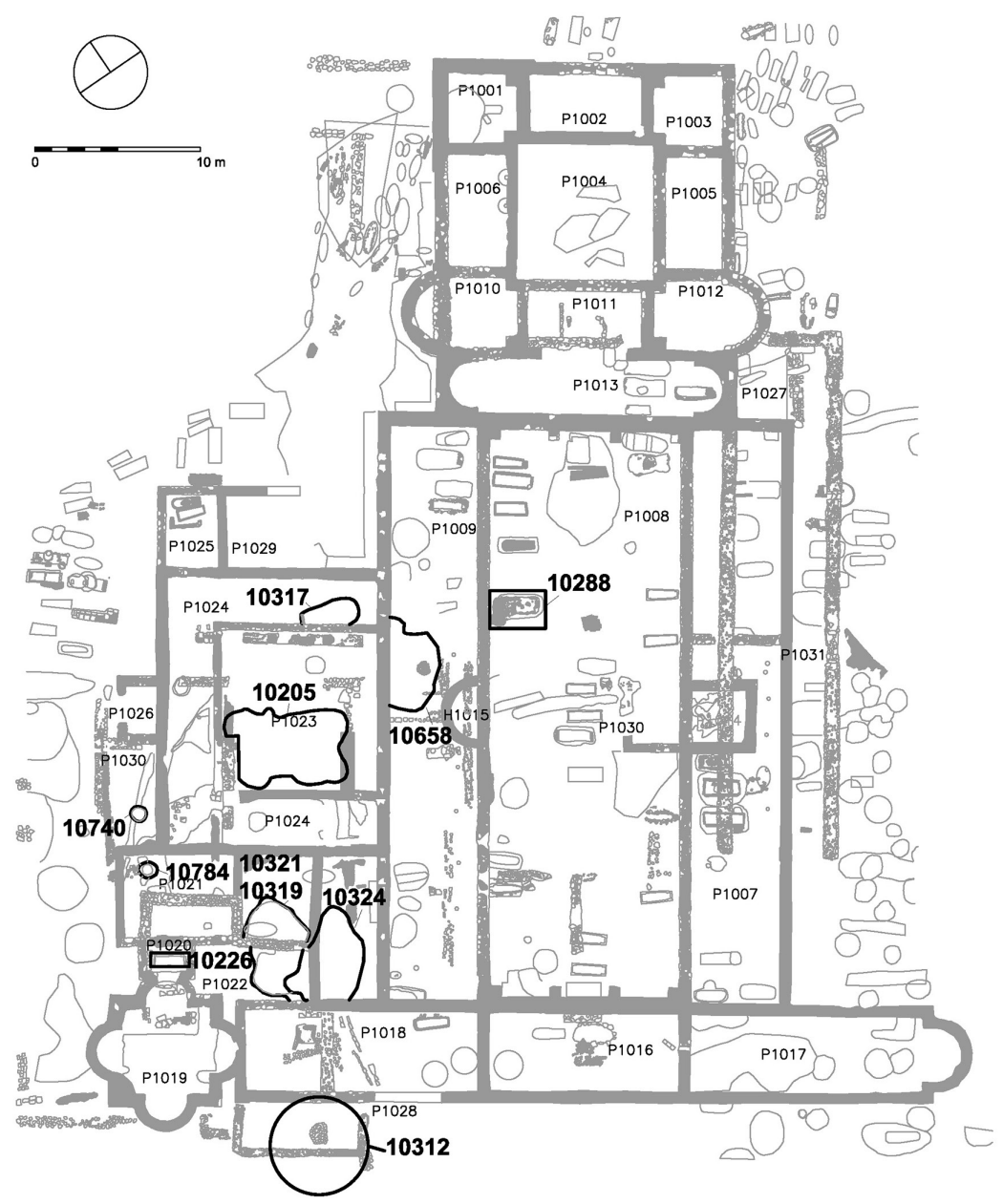

FIG. 4. Localización de las UUEE tardoantiguas estudiadas. referimos a los grupos cerámicos A1, A2, A3, A6 y a8, además de fragmentos de TSHT y TSA. Junto a estos grupos, el estudio llevado a cabo en el edificio palacial ha permitido identificar y caracterizar dos nuevos grupos tecnológicos -A10 y A11-asociados exclusivamente a los horizontes tardoantiguos y hasta ahora no identificados en otras áreas del yacimiento de Santa María de Abajo.

La identificación de los grupos cerámicos del yacimiento se ha realizado a partir de la revisión y estudio de todos los contextos estratigráficos excavados por nuestro equipo. El lector observará que no se alude ahora a alguno de los grupos tecnológicos que fueron detectados en el área del torcularium - 44 , A5 y A7- dado que no han sido localizados en los contextos cerámicos ahora analizados.

\section{Contextos cerámicos tardoantiguos: grupos cerámicos identificados}

Como hemos indicado, presentamos el estudio cerámico de diez UUEE vinculadas con el horizonte tardoantiguo $^{13}$ (Fig. 4). Por razones de claridad

13 Junto con estos grupos cerámicos se han localizado también fragmentos muy rodados de producciones de mesa de cronología altoimperial, tanto Ts indeterminada, como TsH y fragmentos de cerámicas pintadas tipo Meseta Sur. Estos fragmentos cerámicos han sido englobados en la categoría de "materiales residuales" expresada en la Fig. 5. Queremos apuntar que junto con la cerámica presente en todas las uUEe y que constituye el objeto de este estudio, formaron también parte del registro arqueológico de las UUEE 10312, 10658, 10205, 10317, 10319/10321, 10324 10740 y 10784 restos faunísticos. Asimismo, en las UUEE 
expositiva, se presentan ahora las características formales y tecnológicas de los grupos cerámicos identificados en este horizonte para abordar a continuación las características de las unidades estratigráficas objeto de análisis ${ }^{14}$.

\subsection{Grupos tecnológicos cerámicos}

- Grupo A1: cerámica común de mesa realizada a torno, de cocción oxidante. Pastas de color naranja y amarillentas de dureza media, muy decantadas o decantadas con desgrasantes finos y, ocasionalmente, medios, micáceos y cuarcíticos ${ }^{15}$. Aunque mayoritariamente no se conservan evidencias de acabado al exterior -es posible que sea por el estado de conservación de los fragmentos-, hay piezas que muestran un acabado exterior alisado. Desde el punto de vista formal, es posible identificar formas cerradas de tendencia globular -tipo jarra o jarro-, platos o fuentes, cuencos y cubiletes-vasos. En relación con la cronología atribuible a este grupo, se trata de piezas tecnológica y formalmente de clara tradición romana que no presentan, per se, elementos que permitan establecer precisiones cronológicas.

- Grupo A2: cerámica común de mesa realizada a torno de cocción reductora. Pastas de dureza

10312, 10205, 10317, 10319/10321, 10324 y 10784 se hallaron fragmentos varios de marmora procedentes del desmantelamiento de la decoración del edificio palacial. En las UUEE 10658, 10205, 10317, 10319/10321 y 10324 se recuperaron fragmentos informes de hierro, siendo posible identificar clavos en las UUEe 10205 y 10319/10321. En las UUEE 10205 y 10317 hay además elementos informes de bronce; en esta última también un fragmento de plomo. Escorias de metal o vidrio están presentes en las UUEE 10312, 10205 y $10319 / 10321$ y fragmentos informes de vidrio cuyas formas, dado el estado de fragmentación, no pueden ser determinadas, están presentes en las UUEE 10205, 10317 y 10319/10321.

14 Para la cuantificación de los fragmentos de cada uno de los grupos identificados dentro de cada ue $c f$. Fig. 5 .

15 El estudio de los materiales cerámicos se ha realizado a través del análisis macroscópico. Queda pendiente la caracterización arqueométrica de las pastas para esclarecer detalles sobre el origen de la materia prima y los métodos de producción.

(C) Universidad de Salamanca media/dura, muy decantadas con desgrasantes muy finos y micáceos. Presenta las superficies exterior e interior alisadas, generalmente con engobes intensos de color negro. Desde el punto de vista formal, detectamos la presencia de cuencos, cubiletes y jarras/jarros. Del mismo modo que se ha comentado para el grupo Al, se trata de piezas tecnológica y formalmente de clara tradición romana que no presentan, per se, elementos que permitan establecer precisiones cronológicas.

- Grupo A3: cerámica común de mesa realizada a torno de cocción oxidante. Pastas duras de color rosáceo, poco depuradas con desgrasantes medianos y gruesos de tipo cuarcítico y micáceo. Presenta un acabado exterior a base de una aguada blanquecina. Su presencia es muy reducida en los contextos ahora analizados y el estado fragmentado de las piezas impide caracterizar las formas.

- Grupo a6: cerámica común de cocina realizada a torno, de cocción oxidante de poca calidad que, en algunas piezas, puede dar a la pasta un aspecto mixto en algunos sectores. Se utilizan desgrasantes calizos de tamaño grueso -más de $1 \mathrm{~mm}$ - y medio -hasta $1 \mathrm{~mm}$ - y pequeños desgrasantes micáceos. No presenta acabado exterior ni interior aunque puede llevar decoración incisa en algunas partes de la pieza. Desde el punto de vista formal, hemos identificado la presencia mayoritaria de recipientes para la cocción y/o preparación de alimentos, esencialmente ollas junto con orzas y cazuelas. Se aprecian también cántaros con asa de cinta, jarros/jarras, botellas y tapaderas. Un buen número de los fragmentos documentados pertenecientes a este grupo presentan evidencias de fuego por uso. Tampoco en este caso las piezas englobables en este grupo permiten, en función de sus rasgos formales y tecnológicos, establecer precisiones cronológicas.

- Grupo A8: cerámica común de almacenaje de cocción oxidante realizada a torno. Pastas duras de color marrón -claros y oscuros- poco decantadas con desgrasantes gruesos y muy gruesos de carácter cuarcítico. Desde el punto de vista for$\mathrm{mal}$, se trata, en general, de grandes contenedores, tipo dolium, de formas ovoides y labios exvasados. En relación con la cronología atribuible

Zephyrus, LXXX, julio-diciembre 2017, 147-172 
a este grupo, se trata de piezas tecnológica y formalmente de clara tradición romana que no presentan, per se, elementos que permitan establecer precisiones cronológicas.

- Grupo A10: cerámica realizada a mano y a torneta de cocción oxidante o mixta, con desgrasantes muy gruesos de cuarzos y micas abundantes. Se trata de ejemplares de cocina/almacenamiento similares formalmente a los englobados en el grupo A6. Entre las formas atestiguadas, hemos detectado la presencia de ollas de perfil en "s" y botellas. Destaca un ejemplar de contenedor realizado a mano con una cocción baja y de pasta de color anaranjado prácticamente no depurada -10740/11-. Este grupo cerámico está presente tan sólo en las UUEE 10288, 10319/10321, 10658 y 10740 -cf. infra-.

En relación con estas piezas, queremos subrayar que el porcentaje de cerámicas realizadas a torneta y a mano que hemos detectado en el yacimiento de Carranque ${ }^{16}$ es claramente inferior -el 2\%- a los porcentajes documentados en otros yacimientos de la Meseta Sur, no permitiéndonos extraer las conclusiones cronológicas derivadas de los trabajos realizados por Vigil-Escalera ${ }^{17}$. En Carranque, al igual que en el Horizonte I del Tolmo de Minateda fechado entre los ss. VII y primer cuarto del viII, la cerámica a mano y a torneta es escasa (Gutiérrez Lloret et al., 2003: 134; Amorós, 2013), como también sucede en Recópolis a lo largo de toda su secuencia de ocupación (Olmo y Castro, 2008), en Mérida (Alba y Feijoo, 2003) y en la Vega Baja de Toledo (Gómez Laguna y Rojas, 2009; Gallego, 2010: 323; Aranda, 2013). Por otro lado, la presencia de cerámica mayoritariamente a torno

16 Este porcentaje se ha establecido exclusivamente a partir del estudio del material que presentaba evidencias tecnológicas claras, asumiendo la gran dificultad de detectar el uso del torno lento ya expresada con claridad por S. Gutiérrez Lloret (1996: 16-18).

17 Según este autor, la cerámica a torneta irá implantándose en los yacimientos rurales del centro peninsular a partir de mediados del s. vi. A partir de finales del s. vi y a lo largo del vir la cerámica hallada en estos enclaves está, siempre según Vigil-Escalera (1999, 2003, 2007b, 2009b y $2015)$, realizada mayoritariamente a torneta/mano. en el caso de Carranque dificulta la división tradicional entre contextos urbanos y rurales para explicar los distintos porcentajes de cerámicas a torno o a torneta y a mano en los yacimientos estudiados. Igual sucede en aldeas altomedievales de la Cuenca del Duero, donde las producciones cerámicas de este período son también mayoritariamente a torno (Larrén et al., 2003). Así, en los yacimientos de Canto Blanco (Calzada del Coto/Sahagún, León), Ladera de los Prados (Aguasal, Valladolid), Navamboal (Íscar, Valladolid) y La Mata del Palomar (Nieva, Segovia), se constatan conjuntos cerámicos realizados a torno, con una proporción muy baja de torneta no superior al $2 \%$, fechables en época visigoda avanzada (Strato, 2013a: 75-76; 2013b: 93-94; 2013c: 130-132 y 2013d: 148154). Esta tendencia a la elaboración a torno de las producciones de cerámica común tardoantiguas y altomedievales se detecta también en la zona de la actual provincia de Salamanca (Dahí, 2012; Ariño y Dahí, 2012 y Ariño et al., 2015).

- Grupo A11: cerámica común de cocina/almacenamiento realizada a torno de cocción mixta, con desgrasantes de tamaño medio-grande de cuarcitas y micas plateadas y doradas. Presentan un acabado alisado al exterior e interior de la pieza con engobe de color marrón-rojizo. El mayor número de piezas documentadas pertenecen a ollas de secciones netamente tardorromanas; detectamos también una posible jarra de cocina $-10321 / 3-$, siendo abundantes las orzas $-10319 / 15,10784 / 1$ y $10205 / 22,23,30-$ de perfiles igualmente de tradición tardorromana. Documentamos ejemplares con decoración incisa de ondas -10784/1, 10321/66-. Estas cerámicas caracterizadas por sus acabados engobados están presentes en todos los contextos tardoantiguos analizados a excepción de en los rellenos UUEE 10312, 10317 y 10658.

- тsнт: esta producción se documenta exclusivamente en las UUEE 10205 y 10317 - cf. infray, como material residual, en las uUeE 10312 y 10319/10321.

- TSA D: esta producción se documenta exclusivamente en las UUEe 10205 y 10317 - cf. infra- . 


\subsection{Estudio cerámico por unidades estratigráficas (Fig. 5)}

\begin{tabular}{|c|c|c|c|c|c|c|c|c|c|c|c|c|}
\hline & \multicolumn{9}{|c|}{$\begin{array}{l}\text { FASE 2: } \\
\text { HÁBITAT }\end{array}$} & \multicolumn{2}{|c|}{$\begin{array}{c}\text { FASE 3: } \\
\text { NECRÓPOLIS }\end{array}$} & \multirow[b]{2}{*}{$\begin{array}{l}\text { Total / } \\
\text { Grupo }\end{array}$} \\
\hline & $\begin{array}{c}\text { UE } \\
10205\end{array}$ & $\begin{array}{c}\text { UE } \\
10312\end{array}$ & $\begin{array}{c}\text { UE } \\
10317\end{array}$ & $\begin{array}{c}\text { UE } \\
10319\end{array}$ & $\begin{array}{c}\text { UE } \\
10321\end{array}$ & $\begin{array}{c}\text { UE } \\
10324\end{array}$ & $\begin{array}{c}\text { UE } \\
10658\end{array}$ & $\begin{array}{c}\text { UE } \\
10740\end{array}$ & $\begin{array}{c}\text { UE } \\
10784\end{array}$ & $\begin{array}{c}\text { UE } \\
10226\end{array}$ & $\begin{array}{c}\text { UE } \\
10288\end{array}$ & \\
\hline $\mathrm{a} 1$ & 62 & 1 & 11 & 22 & 66 & 18 & 8 & 0 & 0 & 1 & 6 & 195 \\
\hline $\mathrm{a} 2$ & 0 & 3 & 1 & 0 & 0 & 0 & 0 & 0 & 0 & 0 & 0 & 4 \\
\hline a3 & 12 & 0 & 2 & 0 & 4 & 0 & 0 & 0 & 0 & 0 & 0 & 18 \\
\hline $\mathrm{a} 4$ & 0 & 0 & 0 & 0 & 0 & 0 & 0 & 0 & 0 & 0 & 0 & 0 \\
\hline a5 & 0 & 0 & 0 & 0 & 0 & 0 & 0 & 0 & 0 & 0 & 0 & 0 \\
\hline a6 & 184 & 6 & 22 & 61 & 237 & 38 & 24 & 19 & 0 & 0 & 12 & 603 \\
\hline \begin{tabular}{|l}
$a 7$ \\
\end{tabular} & 0 & 0 & 0 & 0 & 0 & 0 & 0 & 0 & 0 & 0 & 0 & 0 \\
\hline $\mathrm{a} 8$ & 1 & 1 & 0 & 0 & 2 & 2 & 1 & 0 & 0 & 0 & 0 & 7 \\
\hline a10 & 0 & 0 & 0 & 1 & 0 & 0 & 5 & 6 & 0 & 0 & 2 & 14 \\
\hline \begin{tabular}{|l|} 
a11 \\
\end{tabular} & 9 & 0 & 0 & 1 & 5 & 4 & 0 & 3 & 10 & 0 & 1 & 33 \\
\hline \begin{tabular}{|l} 
residual \\
\end{tabular} & 5 & 6 & 3 & 2 & 21 & 4 & 2 & 9 & 1 & 0 & 2 & 55 \\
\hline TotAL/UE & 273 & 17 & 39 & 87 & 335 & 66 & 40 & 37 & 11 & 1 & 23 & 929 \\
\hline
\end{tabular}

Fig. 5. Tabla con cuantificación de los fragmentos analizados.

\section{Estudio de los contextos cerámicos de la Fase 2. El hábitat tardoantiguo}

— uE 10205 (Figs. 6-7): relleno de la fosa Ue 10300, localizada en el interior del espacio p1023. Esta fosa se amolda a los límites de los muros de opus caementicium del edificio palacial y su relleno sirve como cimentación a una serie de estructuras murarias pertenecientes a una fase posterior. Los materiales cerámicos presentes en el relleno de esta fosa son de tradición romana con presencia significativa de terra sigillata, principalmente TSHT formas 74/Palol4 -10205/57 y 61- y Rit. 8 -10205/63-, además de fragmentos de galbos con decoración de series de círculos concéntricos tangentes con baquetones longitudinales $-10205 / 55$ y 64-, con decoración de serie de círculos concéntricos con lúnulas -10205/56-, con decoración estampillada de bastones segmentados rectilíneos y motivos florales esquemáticos -10205/54- y un fragmento con decoración de serie de grandes círculos -10205/65-. Están también presentes las producciones africanas de terra sigillata -producción $\mathrm{D}$-, entre las que destaca un fragmento con decoración estampillada con flor de ocho pétalos y palmeta con nervadura central $-10205 / 80-{ }^{18}$. Junto con estas producciones, están también presentes cerámicas de mesa del grupo $\mathrm{A} 1$ y $\mathrm{A} 3$, de almacenamiento del grupo A8 y de cocina del grupo A6, todos ellos grupos ya identificados en el estudio ceramológico realizado en el torcularium de nuestro yacimiento ${ }^{19}$. En este sentido, queremos destacar la presencia de ollas de perfil en "s" y un jarro con pitorro vertedor -gutus- del grupo A6 -10205/9-, formas que no habían sido detectadas en contextos tardorromanos de Carranque. En esta misma unidad están presentes cerámicas del grupo A11, caracterizado, como se ha visto, por el uso de engobes marrones y que tampoco había sido identificado en el estudio cerámico realizado en el torcularium.

La formación de este relleno coincide con el abandono de la función original del edificio palacial;

18 Esta decoración en el fondo de la pieza es típica de platos Hayes 59, 61 y 67. Este tipo de roseta no aparece con anterioridad a la segunda mitad del s. Iv d. C. (Hayes, 1972). Queremos agradecer a A. Fernández sus comentarios sobre las piezas de TSA.

19 Fernández Ochoa et al., op. cit. n. 9. Las cerámicas más tardías detectadas en el estudio realizado en este sector del yacimiento se datan a finales del s. Iv d. C. 
así, la abundante presencia de material lapídeo en el relleno parece confirmar que la construcción estaría, al menos parcialmente, desmantelándose en este momento. En este sentido, queremos destacar que entre el material lapídeo documentado en esta se halla un fragmento de fuste de columna de pavonazzetto perteneciente a la galería porticada del patio.

La presencia de un conjunto reseñable de TSHT fechable en la primera mitad del s. v d. C., junto con los fragmentos identificados de TSA D y la aparición de piezas engobadas del grupo A11

\section{UE 10.205: Grupo A-11}

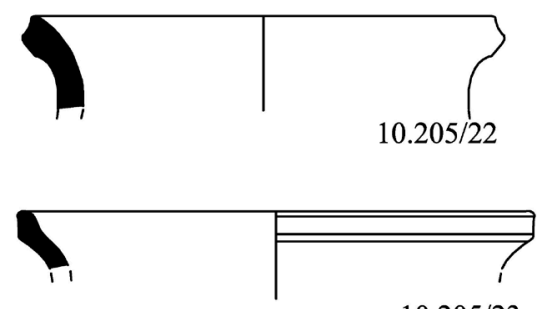

$10.205 / 23$

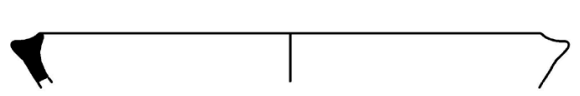

$10.205 / 30$

UE 10.205: TSA D

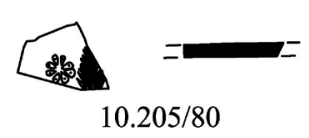

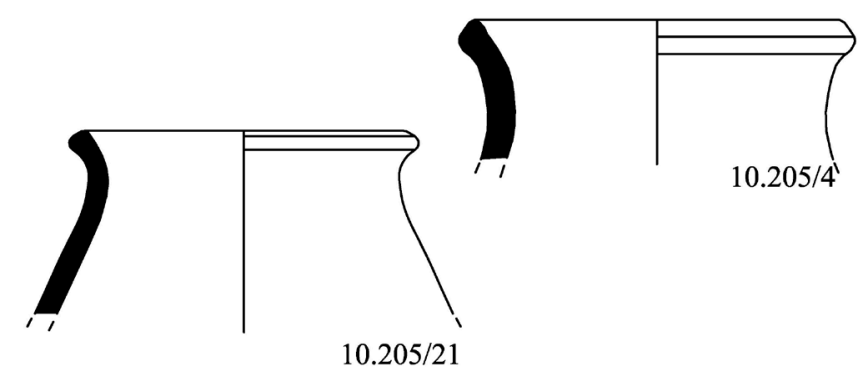

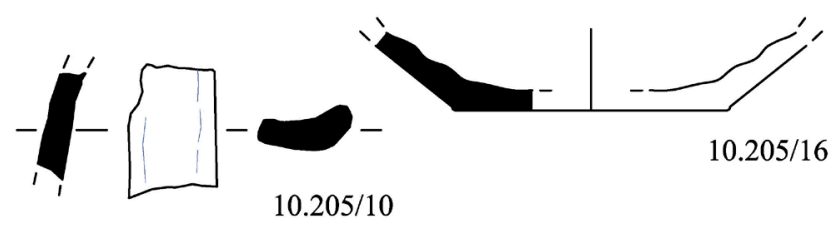

UE 10.205: TSH

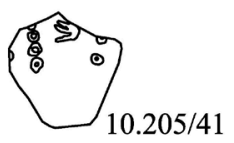

\section{UE 10.205: TSHT}

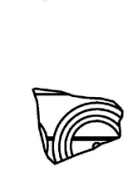

$10.205 / 55$

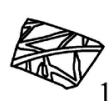

$10.205 / 65$

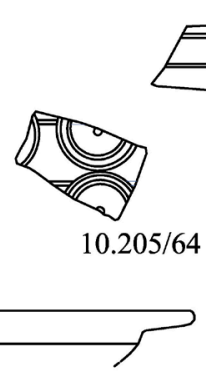

$10.205 / 57$
$10.205 / 56$
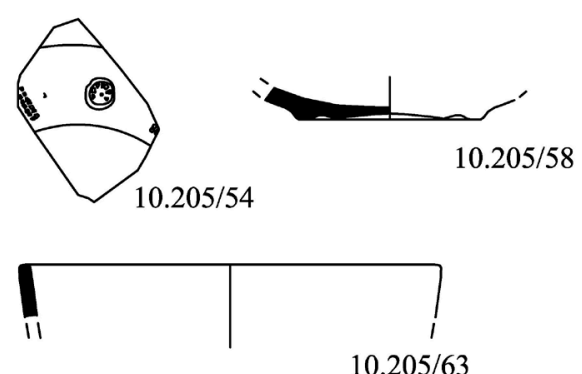

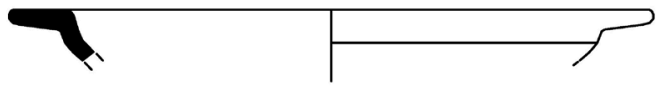

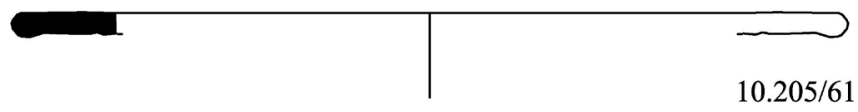

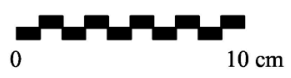

FIG. 6. Cerámica asociada a la UE 10205. 
inéditas hasta el momento en los contextos tardorromanos del yacimiento, nos llevan a plantear una cronología en torno a mediados del s. $\mathrm{v}$ d. C. para la formación de este relleno.

- uE 10312 (Fig. 8): unidad sedimentaria formada esencialmente por ceniza que asociamos al uso de las estructuras de combustión localizadas en la zona meridional del edificio palacial. Estas estructuras están formadas por fragmentos de material latericio colocados en el terreno formando una pequeña cuenca que aparecieron cubiertas por este nivel ceniciento. El material cerámico es muy escaso, tan sólo algunos fragmentos de cerámica de mesa $-\mathrm{A} 1-\mathrm{y}$ cerámica de cocina y almacenamiento de los grupos a6 y a8 típicamente romanas -ollas de borde exvasado de labio

UE 10.205: Grupo A-1

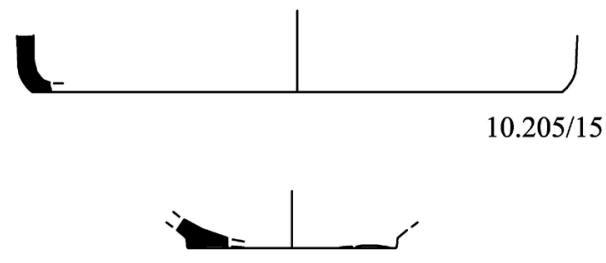

$10.205 / 31$

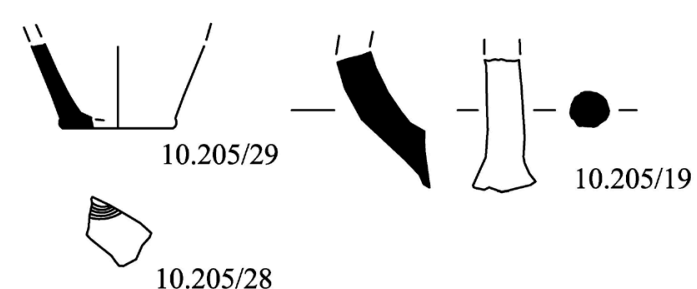

$10.205 / 28$

\section{UE 10.205: Grupo A-6}
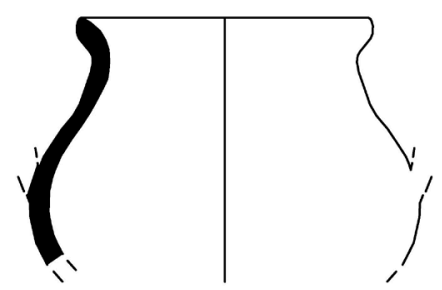

$10.205 / 14$

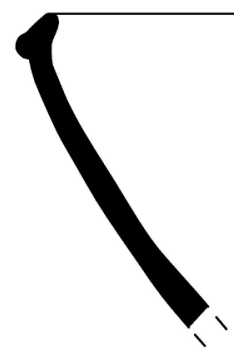

UE 10.205: Grupo A-8

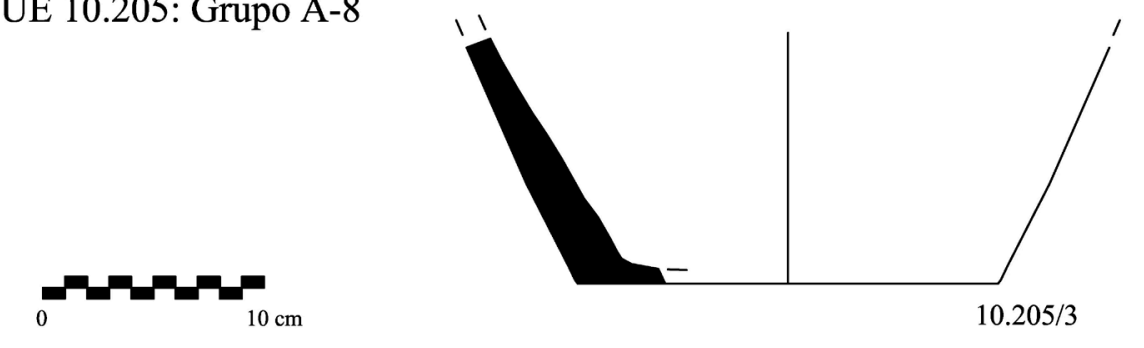

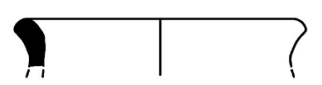

$10.205 / 18$

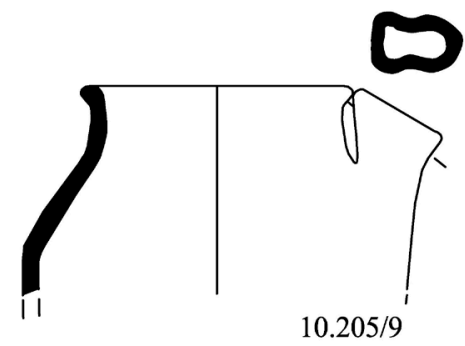

$10.205 / 9$

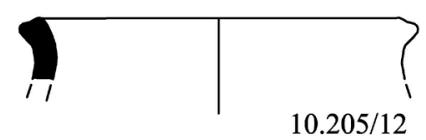

$10.205 / 12$

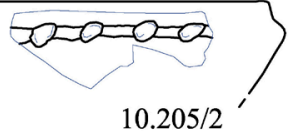

$10.205 / 2$

$10.205 / 1$

FIG. 7. Cerámica asociada a la UE 10205. 
UE 10.312: Grupo A-1
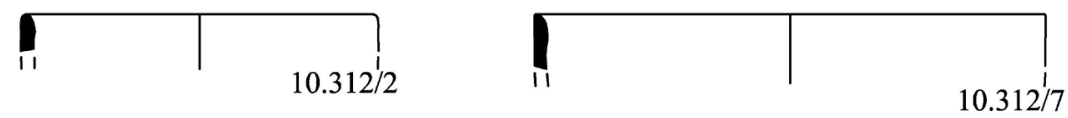

UE 10.312: Grupo A-6

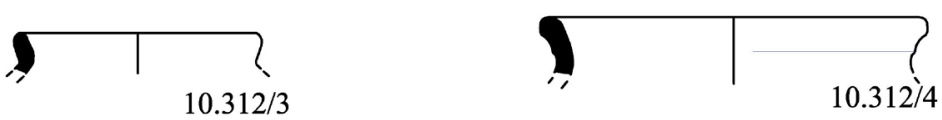

UE 10.312: Grupo A-8

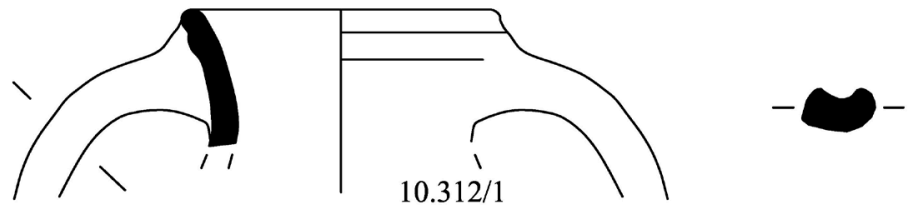

UE 10.312: TSHT

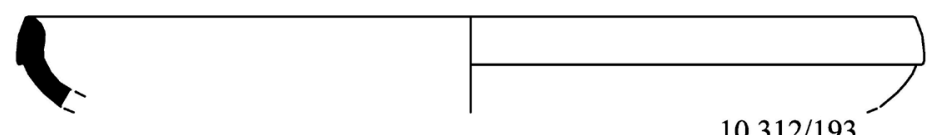

$10.312 / 193$

UE 10.317: Grupo A-2

UE 10.317: Grupo A-6

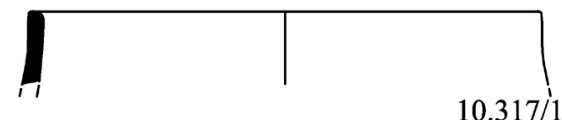

UE 10.317: TSHT

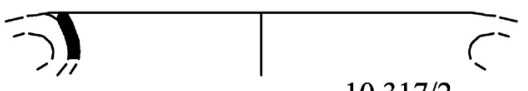

$10.317 / 2$

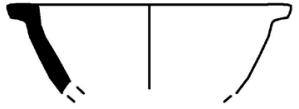

$10.317 / 6$

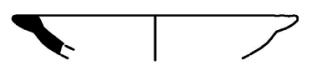

$10.317 / 7$

UE 10.317: TSA D
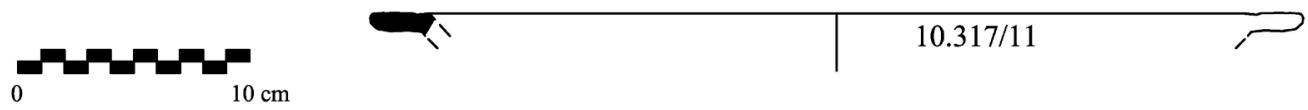

FIG. 8. Cerámica asociada a las UUEE 10312 y 10317.

redondeado y cuencos de paredes rectas-. Se localiza también un fragmento de borde de TSHT, que se corresponde con una Forma 71/Palol 2/Paz 83.B que este último investigador fecha en un momento post quem a c. 420-430 (Paz, 2008: 507).

- uE 10317 (Fig. 8): se trata del relleno de la fosa UE 10352, localizada en la p1024. El material cerámico asociado a este relleno es escaso destacando algunos fragmentos de cerámica de mesa de los grupos A1-A3, junto a cerámica de cocina del grupo A6 en mayor número, en ambos casos sin rasgos morfológicos reseñables. Cabe destacar dos fragmentos de тSHт (10317/6 y 7) Forma 6/Palol 8/Paz 6.4 que no ofrecen una 
UE 10.319/10.321: Grupo A-1
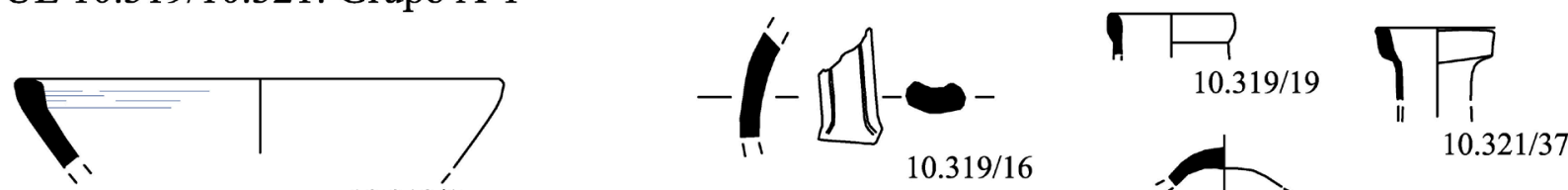

$10.319 / 17$

$10.321 / 38$

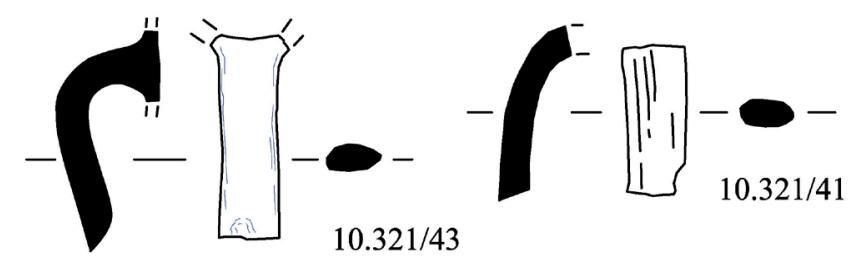

UE 10.319/10.321: Grupo A-6
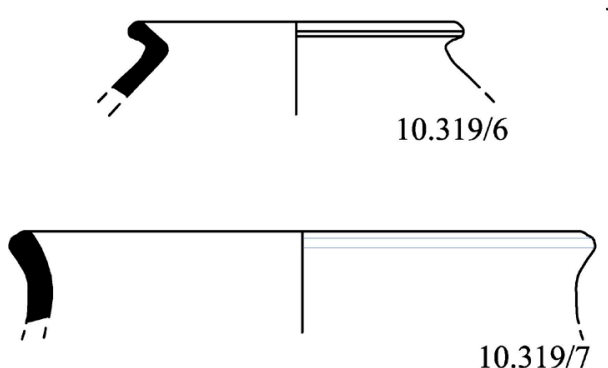

$10.319 / 7$
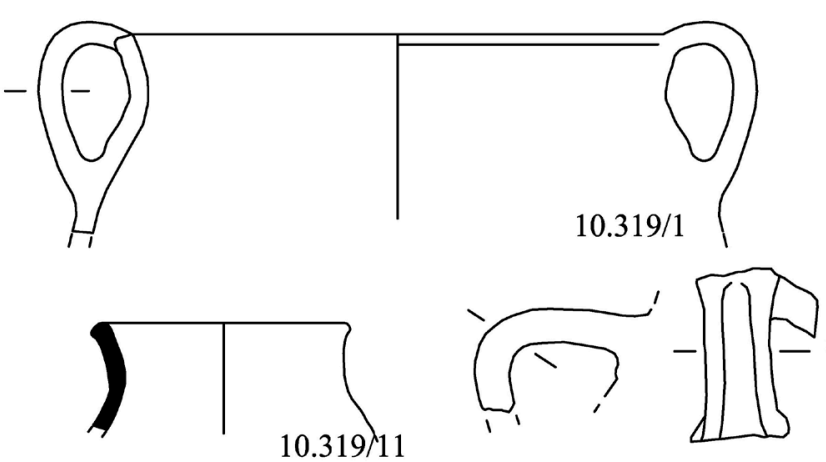

$10.319 / 1$

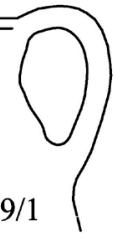

$10.319 / 3$

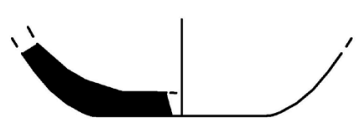

$10.319 / 4$

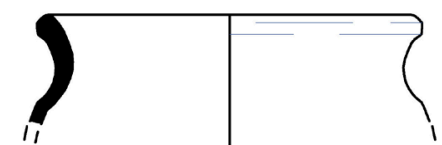

$10.321 / 53$

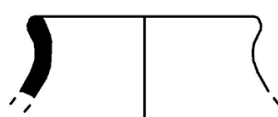

$10.321 / 35$

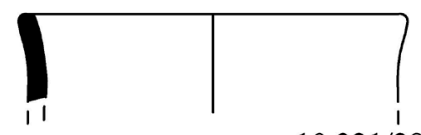

$10.321 / 28$

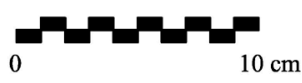

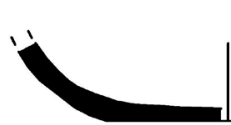

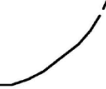

$10.319 / 10$
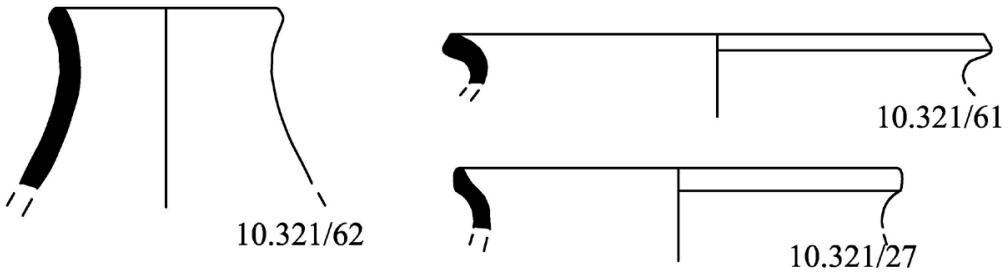

$10.321 / 27$

$10.319 / 5$

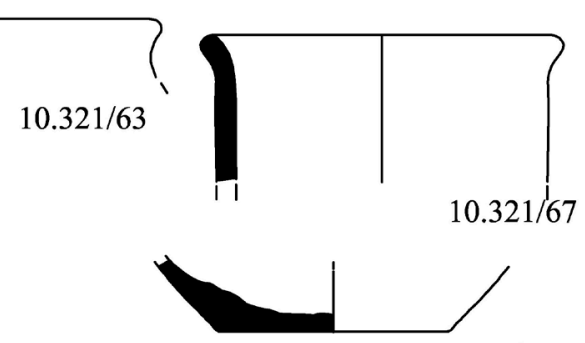

$10.321 / 19$

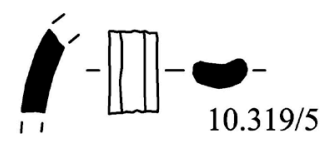

$10.321 / 1$

FIG. 9. Cerámica asociada a la UE 10319/10321. 
cronología precisa (Juan Tovar, 2000: 92; Paz Peralta, 2008: 525) y un tercer fragmento de TSA D, forma Hayes 59в (10317/11) que Hayes fecha en un momento entre 320 y $420 \mathrm{~d}$. C. (Hayes, 1972: 96-100) y que en la Península Ibérica se asocia a contextos de finales del s. IV a mediados del v d. C. (Fernández Fernández, 2014: 156-158). Al igual que ocurre con el relleno 10205 , la formación de este estrato coincide con el abandono de la función original del edificio palacial que estaría desmantelándose, como así pone de relieve el abundante material lapídeo localizado, entre el que destacamos varios fragmentos de sillares de granito pertenecientes, en origen, al zócalo del edificio.

- ue 10319/10321 (Figs. 9 y 10): se trata del relleno de la fosa ue 10353, localizada en el interior de la habitación p1022. Esta fosa y su relleno se amoldan a los límites de uno de los muros de opus caementicium del edificio palacial y aparecen cubiertos por muros pertenecientes a una fase posterior. Desde el punto de vista estratigráfico, debemos subrayar que tanto este relleno como la fosa que lo acoge fueron cortados por la fosa 10355. Asimismo, hemos localizado la presencia de la tumba 1/1996 perteneciente a la necrópolis de época visigoda, excavada en este relleno ${ }^{20}$. Aparecen cerámicas de mesa-cuencos y botellas del grupo A1- y cocina, tanto de tradición tardorromana -esencialmente ollas de fondo plano y orzas del grupo A6-, como tardoantigua, con piezas con engobe marrón -orzas, ollas y lebrillos del grupo A11-, en algunos casos con decoración incisa a peine -10321/66-, y también una botella del grupo A10 realizada a torneta/mano-10319/2-. Están también presentes de forma muy residual fragmentos de TSH, TSHB y тSHт. Queremos destacar la abundancia de ollas con perfil en "s" del grupo A6 y la ausencia de bases convexas.

- UE 10324 (Fig. 11): relleno de la fosa ue 10355 , localizada en el interior de la habitación p1022. Esta fosa y su relleno se amoldan a los límites de los muros de opus caementicium del edificio palacial

20 Cf. García-Entero et al., op. cit. n. 3. y aparece cubierta por muros pertenecientes a una fase posterior. Como se ha mencionado, la fosa 10355 cortó la fosa 10353 y su relleno 10319/10321. Se localiza esencialmente material cerámico de cocina tanto del grupo A6 como del grupo A11, con presencia muy residual de terra sigillata. Destaca una pieza del grupo A11 con pico vertedor -10324/9- destinada posiblemente a la decantación de líquidos, de acabado engobado marrón tanto al exterior como al interior. En este relleno están presentes bases convexas.

— UE 10658 (Fig. 12): unidad sedimentaria situada por debajo de una estructura de combustión y del nivel de uso generado por ésta localizada en el corredor $\mathrm{P} 1009$. A pesar del escaso material cerámico asociado a esta unidad, queremos destacar la presencia de fragmentos de ollas pertenecientes al grupo a6 con formas de tradición tardorromana y bases planas. Al igual que ocurre con los materiales de la UE 10312, están ausentes de este contexto las producciones de los grupos A10 y A11, así como las formas de perfil en "s" que creemos indicadores cronológicos claros de contextos tardoantiguos más avanzados.

— UE 10740 (Fig. 12): relleno inferior del silo UE 10397, localizado en el exterior occidental del edificio palacial. Destaca la escasa presencia de material cerámico, casi exclusivamente cerámica de cocina -A6 y A 10 - con ollas de perfil en "s" con bases planas y también bases ligeramente convexas con rebaba. Destaca la presencia de la parte inferior de un recipiente del grupo A10 de forma globular y base plana, realizado a mano y cocido a baja temperatura con la pasta escasamente decantada -10740/11-. Como ya se ha indicado a propósito de las UUeE 10226 y 10288, la presencia de bases convexas parece configurarse como indicativo cronológico de un momento visigodo avanzado. También corrobora esta afirmación el acentuado perfil en "s" de algunas de las piezas de este contexto. Desde el punto de vista estratigráfico apenas se puede apuntar que este silo corta tanto el nivel geológico como una pequeña zanja fechada con anterioridad a la construcción del edificio palacial. 
UE 10.319/10.321: Grupo A-6

UE 10.319/10.321: Grupo A-8
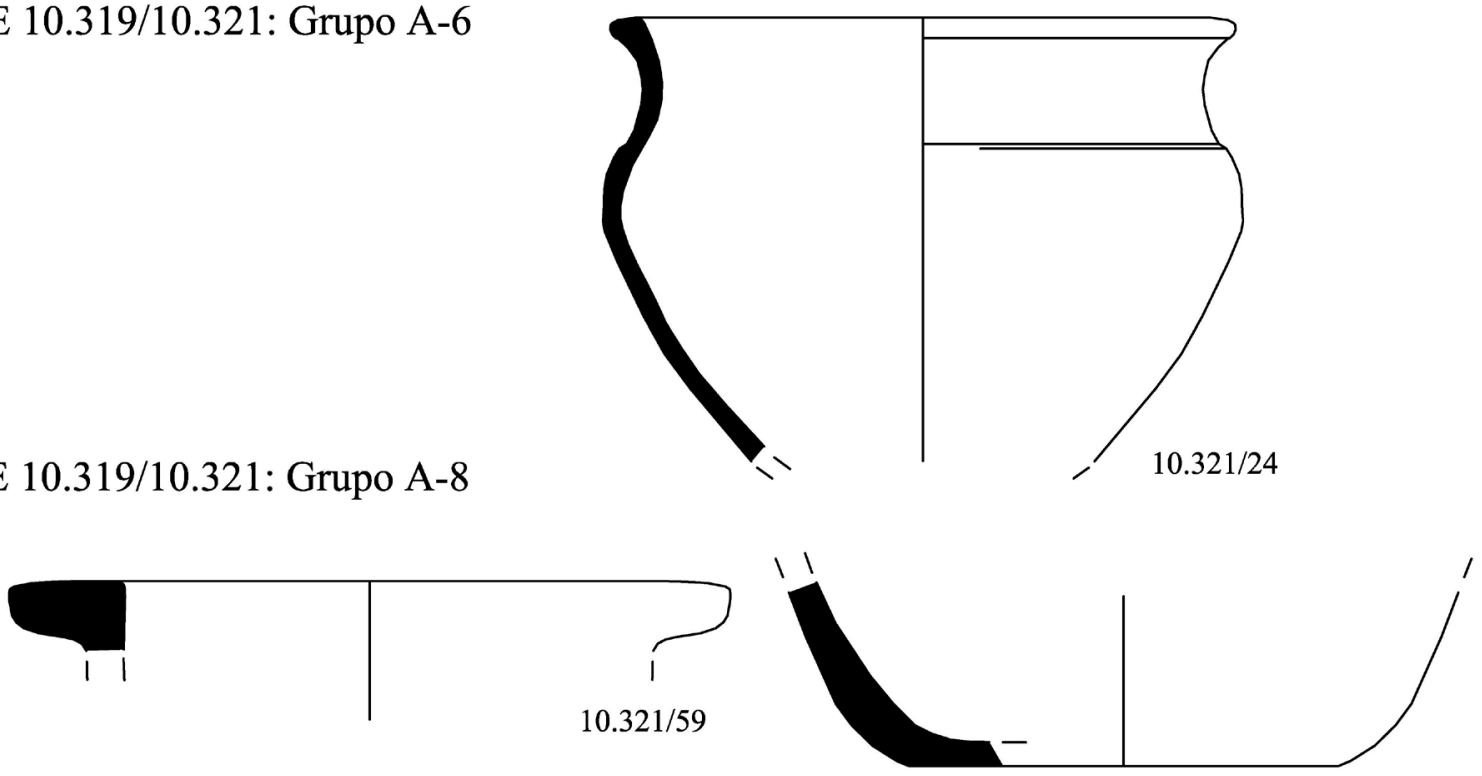

UE 10.319/10.321: Grupo A-10

UE 10.319/10.321: Grupo A-11

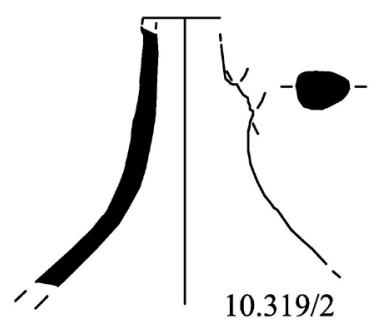

$10.321 / 5$

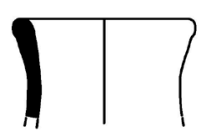

$10.321 / 47$

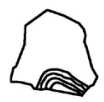

N

$10.321 / 46$
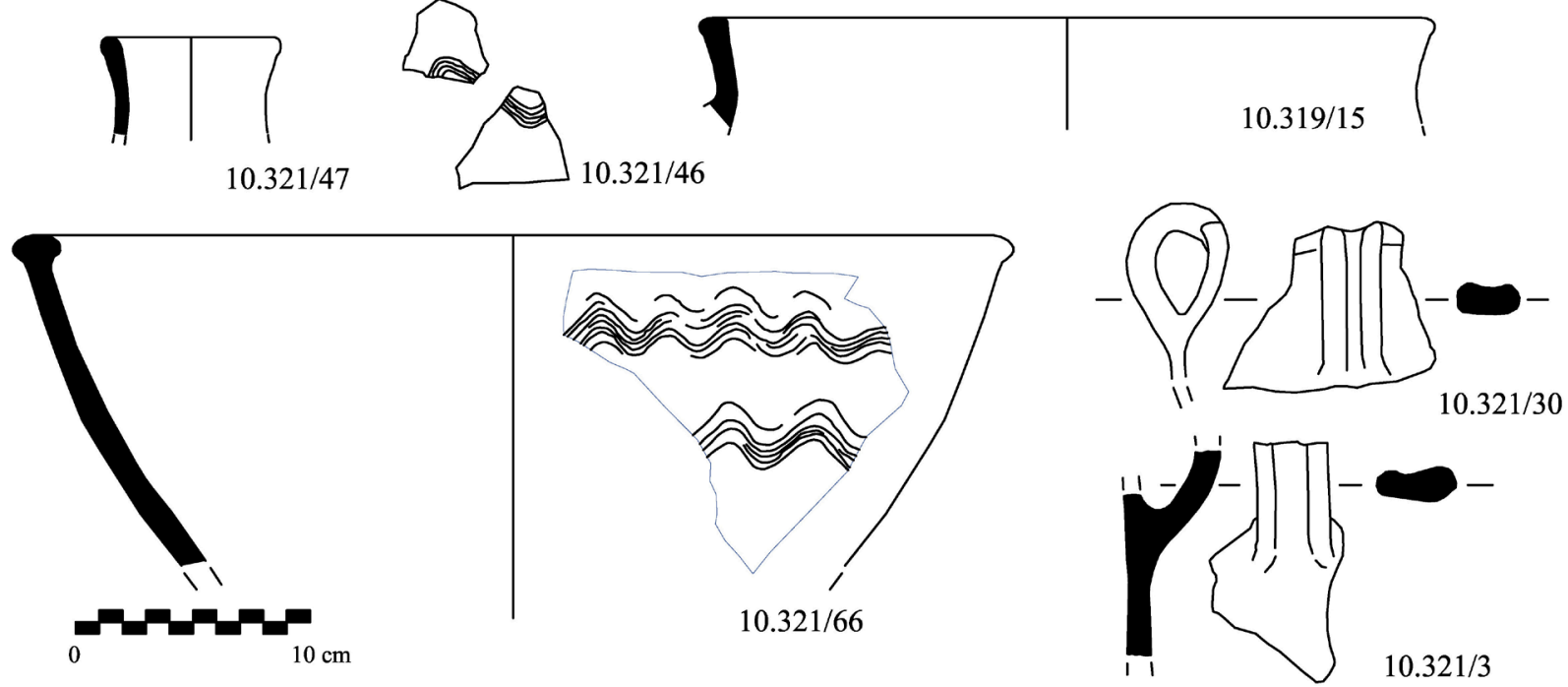

FIG. 10. Cerámica asociada a la UE 10319/10321.

- UE 10784 (Fig. 12): relleno del silo -UE 10783localizado en la habitación P1021, situada en el lateral occidental del edificio palacial. Apenas se localiza una pieza incompleta de una orza con engobe marrón y decoración incisa de ondas perteneciente al grupo A11. Desde el punto de 
164 V. García, Y. Peña, E. Zarco y R. Aranda / Contextos cerámicos tardoantiguos procedentes del edificio palacial...

UE 10.324: Grupo A-1

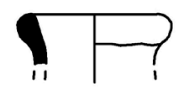

$10.324 / 11$

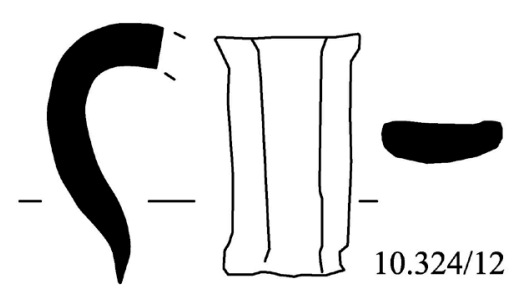

UE 10.324: Grupo A-6

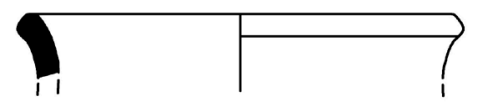

$10.324 / 3$

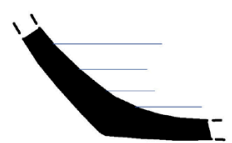

-

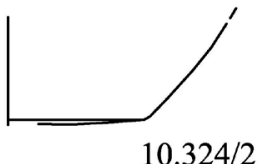

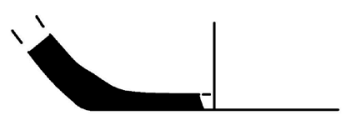

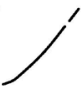

$10.324 / 8$

UE 10.324:Grupo A-8
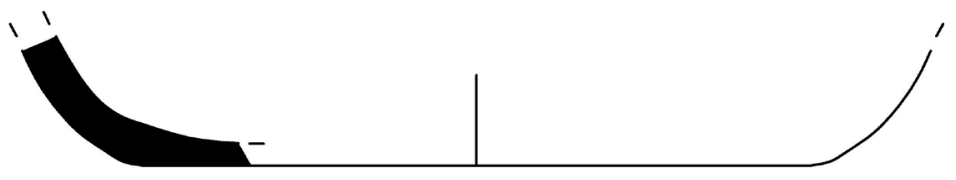

$10.324 / 7$

\section{UE 10.324: Grupo A-11}
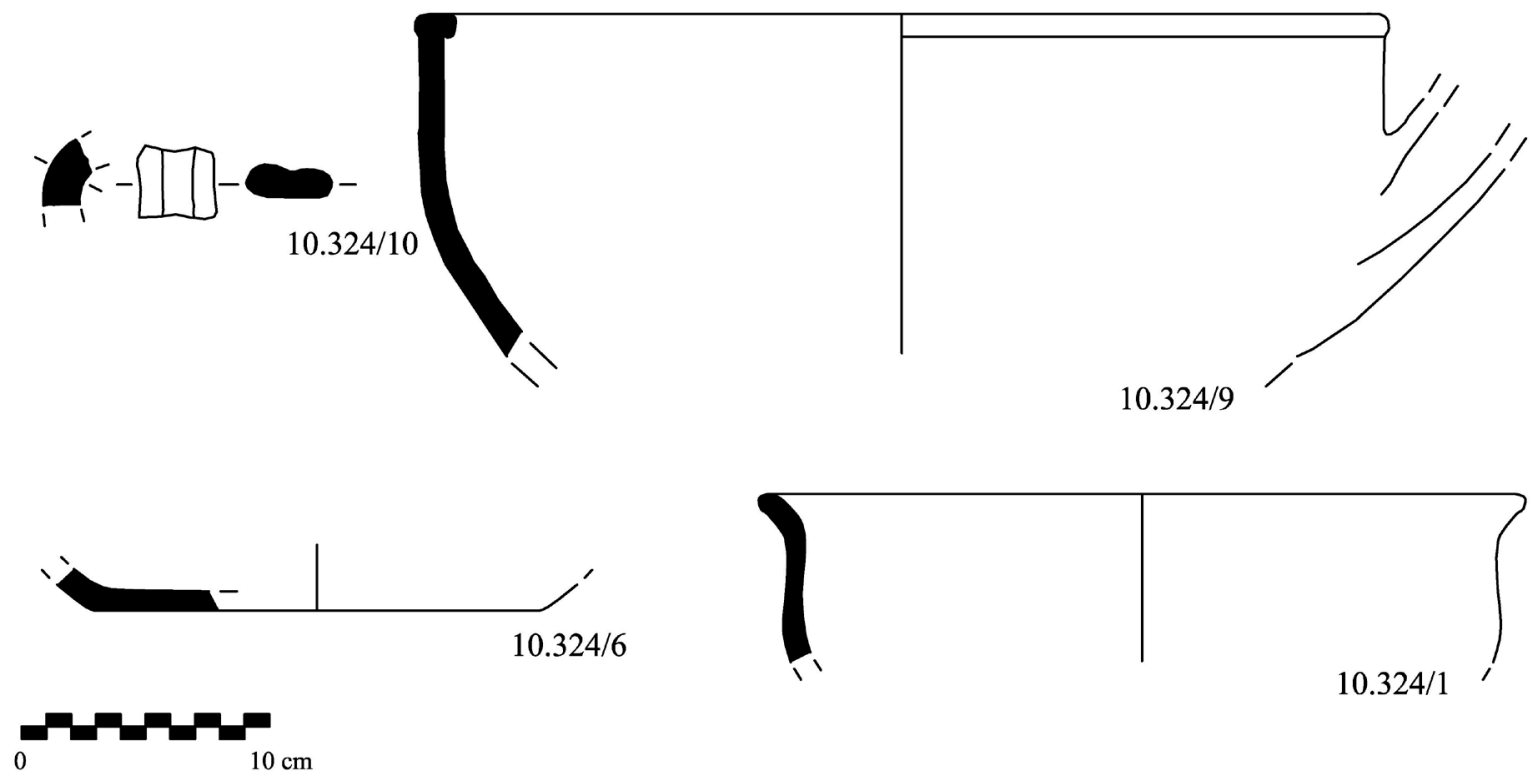

FIG. 11. Cerámica asociada a la UE 10324. 
UE 10.658: Grupo A-1

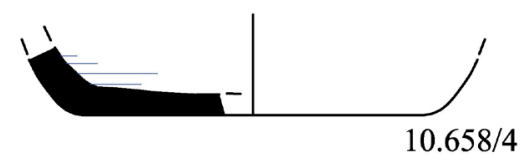

UE 10.658: Grupo A-6
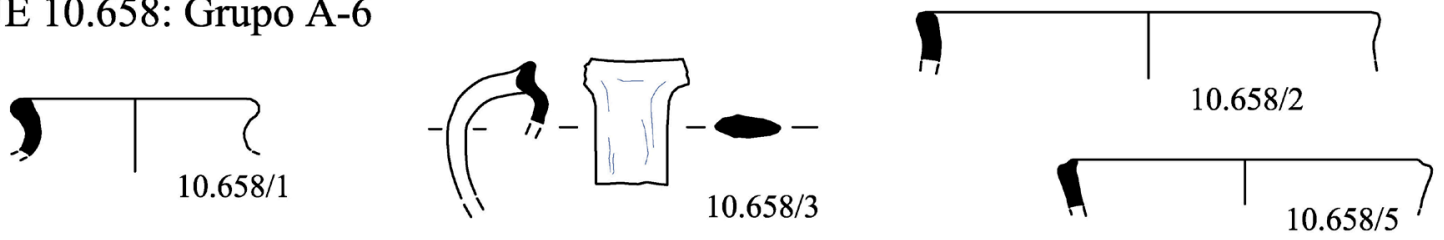

UE 10.740: Grupo A-6

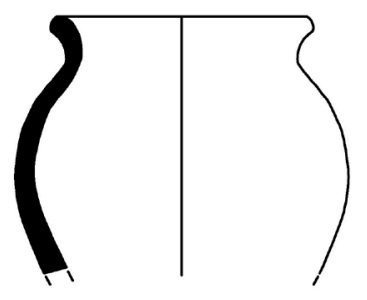

$10.740 / 6$

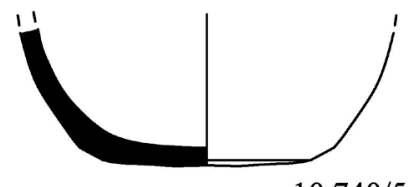

$10.740 / 5$

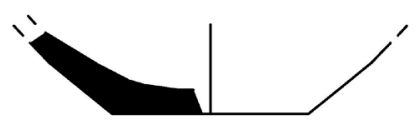

$10.740 / 8$
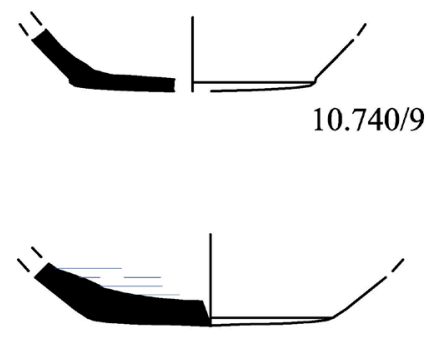

$10.740 / 7$

UE 10.740: Grupo A-10

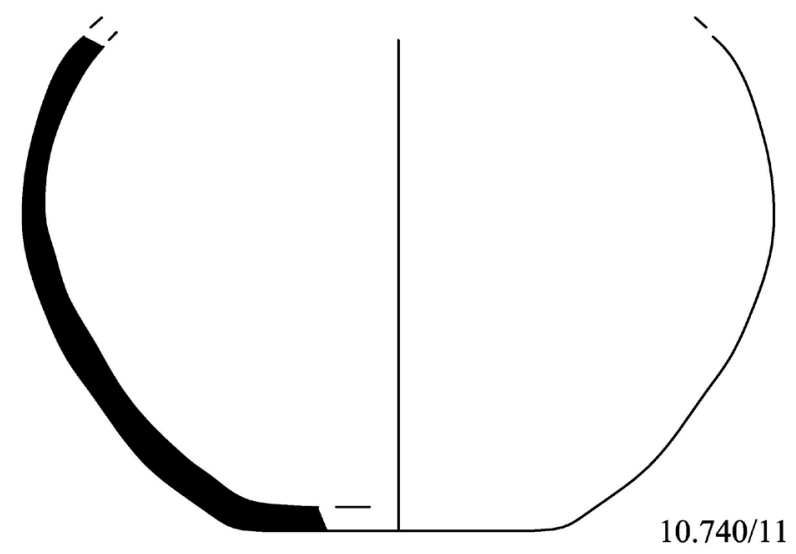

UE 10.784: Grupo A-11
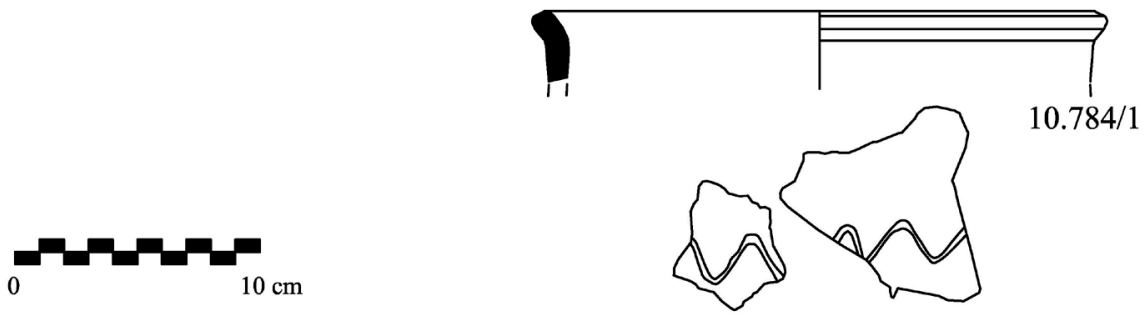

FIG. 12. Cerámica asociada a las UUEE 10658, 10740 y 10784. 
vista estratigráfico, podemos mencionar que la estructura negativa rompió elementos asociados a las fases 0 y 1 .

UE 10.226: Grupo A-1
6. Estudio de los contextos cerámicos de la Fase 3. La necrópolis

- UE 10226 (Fig. 13): corresponde a la inhumación de la Tumba 1 localizada en la habitación

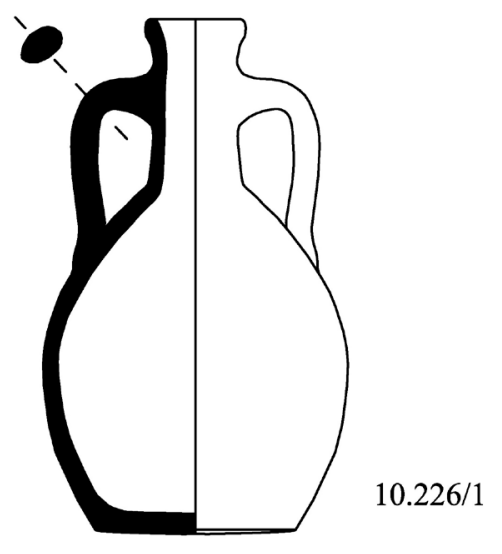

UE 10.288: Grupo A-6

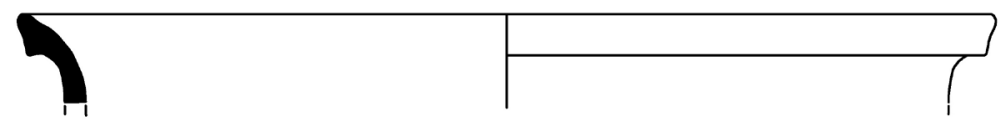

$10.288 / 3$

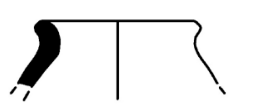

$10.288 / 12$
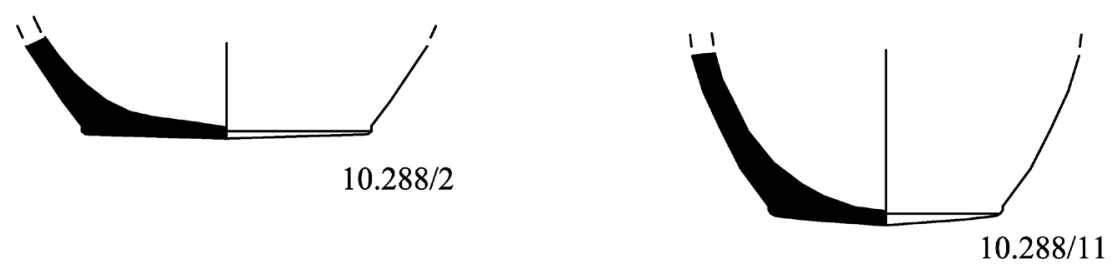

UE 10.288: Grupo A-11

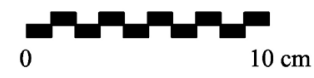

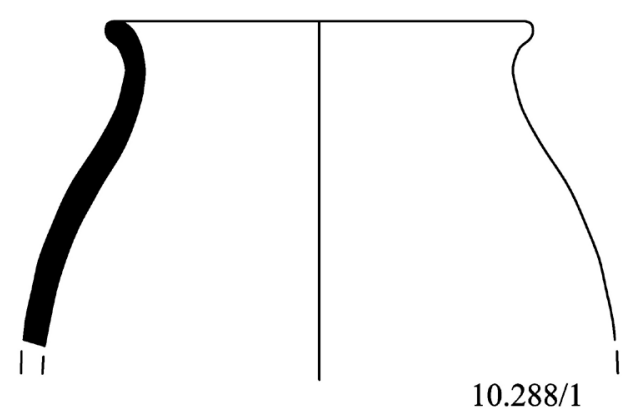

$10.288 / 1$

FIg. 13. Cerámica asociada a las UUEE 10226 y 10288. 
p1019 del edificio palacial ${ }^{21}$. Se trata de una inhumación individual que presenta como ajuar una botella $-10226 / 1$ - perteneciente al grupo A1, de perfil piriforme, base ligeramente conve$\mathrm{xa}$, con dos asas de sección oval y gollete con borde exvasado y labio redondeado. Esta pieza coincide con el tipo 9 de Román $(2007,115$ 116), el 12A de Izquierdo (1977: 850-851) y el tipo $1 \mathrm{~B}$, formas piriformes y base convexa, de Barragán (2012: 258-261). Se trata de una forma muy habitual en contextos funerarios de época visigoda ${ }^{22} \sin$ que, hasta el momento, se haya podido concretar su cronología, fechándose de forma genérica en los ss. VI-VII. En Carranque sabemos que la necrópolis se formó con certeza, al menos, a mediados del s. vi d. C. y encontramos la presencia de bases convexas en el relleno de la tumba 154 cuyo período de uso se fecha por radiocarbono entre 550-660 d. C. (vid. infra).

- UE 10288 (Fig. 13): se trata del relleno de la tumba 154, perteneciente a la necrópolis de época visigoda y localizada en el patio central -P1008-del edificio palacial ${ }^{23}$. Debemos señalar

21 Ocupando por completo la exedra norte de la sala tetralobulada -P1019-, se halla un enterramiento sellado por una losa de yeso, localizado en las intervenciones antiguas y excavado en 2009. Se trata de una inhumación individual en posición primaria decúbito supino, en dirección O-E, que presenta, como ajuar, una botella de cerámica localizada en el ángulo no del enterramiento, a la altura de la cabeza del difunto. El estado de conservación de los restos óseos era pésimo, lo que ha impedido tomar una muestra para la realización de análisis radiocarbónicos. $C f$. también García-Entero et al., op. cit. n. 3.

22 Sobre las posibles interpretaciones rituales de estas piezas de cerámica, habituales como ajuar en las necrópolis de época tardoantigua en la península Ibérica, remitimos a los trabajos de Fuentes, 1989; Carmona, 1998; Flörchinger, 1998; Román, 2007 y Gimeno y Sastre, 2009.

23 Localizada en el lateral occidental del patio (P1008), la tumba fue identificada y excavada en 2010. Con orientación O-E, presenta, al menos, cinco inhumaciones. El relleno excavado (UE 10288) está formado esencialmente por material constructivo, posiblemente perteneciente en origen a las sucesivas cubiertas que tuvo la estructura. También se documentan restos de madera que pudieron haber pertenecido al ataúd de alguna de las inhumaciones realizadas en esta que se trata de una tumba que albergó un mínimo de 5 individuos depositados en, al menos, tres momentos en un arco temporal que los estudios de carbono 14 realizados sitúan entre el 550 y el 660 d. C. ${ }^{24}$. Este relleno se dispone, por tanto, coincidiendo con la última de las inhumaciones de la tumba -UE 10650- fechada por radiocarbono entre 600 y 660 d. C. y presenta escaso material cerámico entre el que destacan fragmentos de cerámica de cocina de los grupos a6 y A11, con ollas de perfil en " $\mathrm{s}$ " y bases ligeramente convexas con rebaba. Como hemos indicado para el material de la UE 10226, la presencia de bases convexas parece constituir un indicativo cronológico de su adscripción a época visigoda avanzada ${ }^{25}$.

\section{Conclusiones}

El estudio de los diez contextos cerámicos seleccionados del horizonte tardoantiguo del yacimiento de Carranque procedentes del espacio ocupado por el edificio palacial tardorromano nos ha permitido

tumba. Asociada a la inhumación superior (UE 10650), en la zona de la pelvis se ha recuperado una hebilla de cinturón rectangular -sin aguja- de hierro. Por otra parte, vinculado con alguna de las reducciones situadas en la parte baja de la tumba (UE 10652), se ha recuperado un anillo de plata con inscripción incisa. Cf. también García-Entero et al., op. cit. n. 3.

24 Se han realizado análisis radiocarbónicos a los restos óseos de las unidades 10650 (último individuo inhumado) y 10652 (correspondiente a los restos de uno de los individuos localizados en la reducción). Los análisis se han llevado a cabo en el laboratorio beta AnalyticInc por M. A. Tamers y D. G. Hood referenciados a la base de datos IntCal13. Los resultados son:

- UE 10652 (Beta-421969, hueso humano): calibratedResult (2б/95\% probability): Cal AD 550-650 $\left({ }^{14} \mathrm{C}\right.$ BP $1460 \pm 30)$.

- UE 10650 (Beta-421970, hueso humano): calibratedResult (20/95\% probability): Cal AD 600-660 $\left({ }^{14} \mathrm{C}\right.$ BP $1410 \pm 30)$.

25 En la fase IA de Melque, fechada en el s. vir avanzado, se localizan bases convexas y planas (Caballero et al., 2013), al igual que en el Horizonte I (s. viI y primer cuarto del viII) del Tolmo de Minateda (Gutiérrez et al., 2003: 134; Amorós, 2013). 
identificar siete grupos tecnológicos. Algunos de ellos -A1-A3, A6, A8- de clara tradición tardorromana, además de fragmentos de TSHT y TSA, ya habían sido localizados en investigaciones previas en otro sector del yacimiento; junto a ellos, la aparición de dos nuevos grupos cerámicos -A10 y A11-, que a tenor del estudio llevado a cabo podemos vincular con el horizonte tardoantiguo, nos permite comenzar a

\section{FASE 2: PRIMER MOMENTO DE OCUPACIÓN}

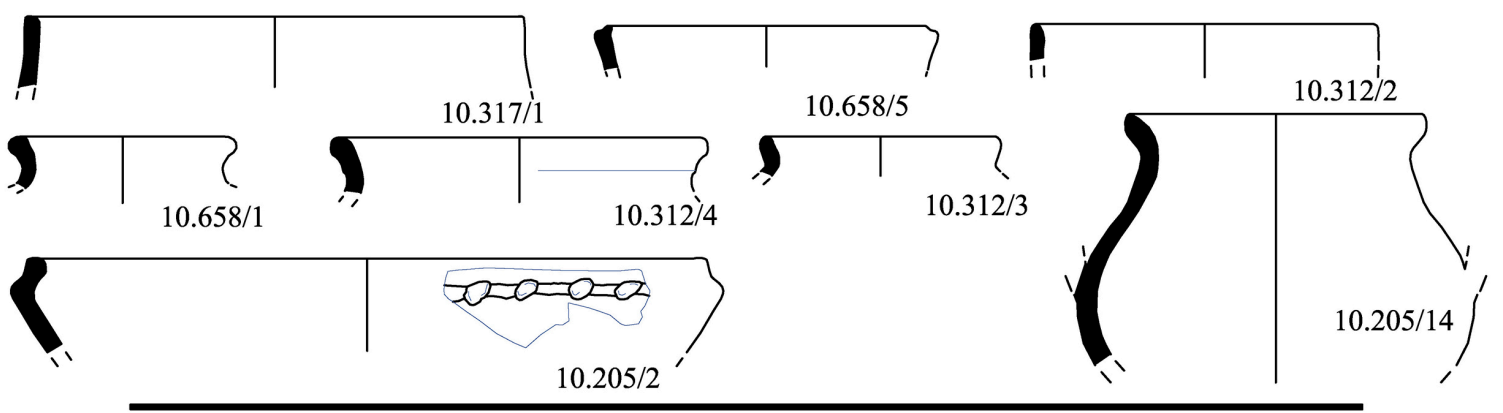

FASE 2: SEGUNDO MOMENTO DE OCUPACIÓN

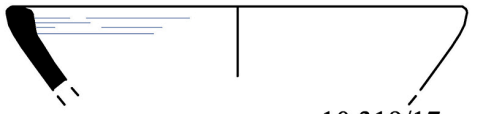

$10.319 / 17$
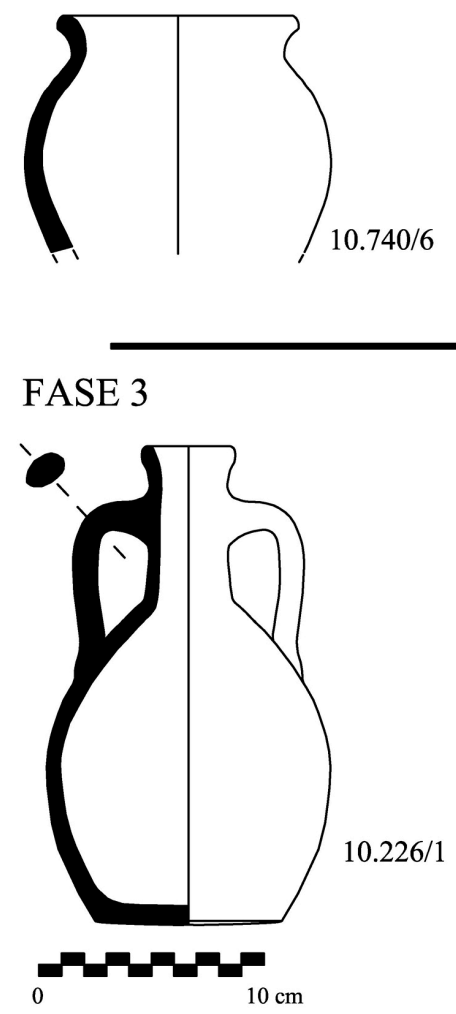

$10.226 / 1$
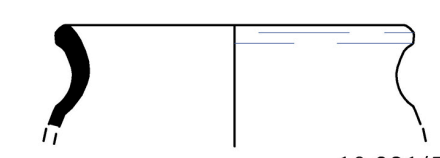

$10.321 / 53$

\section{FASE 3}
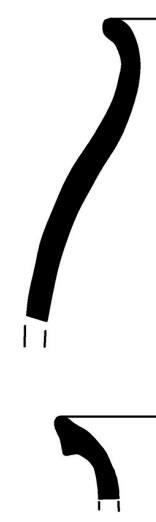

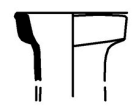

$10.321 / 37$
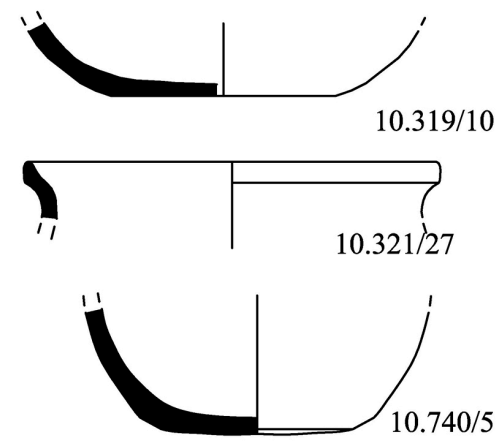
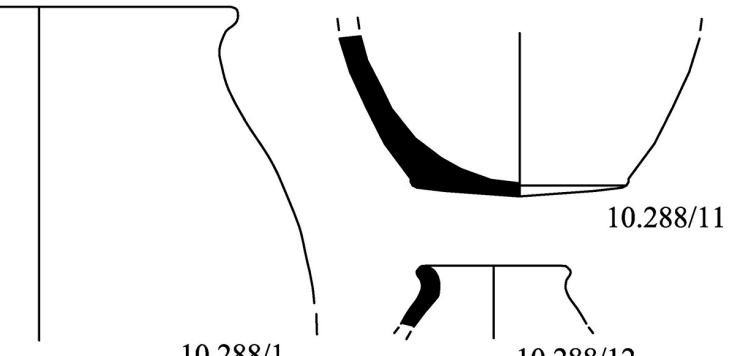

$10.288 / 1$

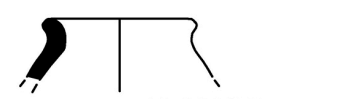

$10.288 / 12$

FIG. 14. Tabla cronotipológica de los materiales analizados. 
caracterizar los ritmos de la ocupación tardoantigua en este solar (Fig. 14). Tres de los grupos identificados -al margen de las producciones de sigillata mencionadas- están dedicados al servicio de mesa -A1-A3- compuesto por jarras/jarros, platos/fuentes, cuencos, cubiletes y vasos con formas de tradición tardorromana y acabados alisados al exterior, siendo destacables los acabados de engobes negros del grupo A2. Tres de los grupos identificados estuvieron destinados a la cocción y preparación de alimentos -A6, A10 y A11-, siendo las formas más habituales las ollas, orzas, cazuelas junto a botellas, jarros/jarras y tapaderas. En este caso, cabe destacar el grupo A10 que, aunque muy similar formalmente al grupo A6, se caracteriza por su elaboración a torno lento o torneta. Por su parte, destacan los acabados de engobado rojizo del grupo A11. Los grandes contenedores de almacenaje se engloban en el grupo A8. Como se ha visto, los fragmentos identificables de TSHT se corresponden con las Formas 74/Palol 4, 71/Palol 2, 6/Palol 8 y Ritt. 8 además de fragmentos decorados fechables, todos ellos, en la primera mitad del s. v d. C. Por su parte, los dos fragmentos de TSA D identificados se corresponden con la Forma Hayes 59в -10317/11y Hayes 59, 61 o 67, cuya cronología puede situarse entre fines del s. IV y mediados del v d. C.

A la luz del estudio de los 10 contextos cerámicos y de su posición estratigráfica podemos identificar tres momentos cronológicos pertenecientes al horizonte tardoantiguo desarrollado sobre el espacio del edificio palacial del yacimiento de Carranque. Los dos primeros se encuentran vinculados a la segunda fase de ocupación del edificio palacial, que coincide con estructuras de hábitat; el tercero se asocia a la necrópolis que se conforma en la Fase 3. Detectamos, así, la presencia de una primera fase de ocupación-Fase 2-, a la que asociamos dos niveles de uso -UUEE 10312 y 10658- vinculados a estructuras de combustión, junto a los rellenos -UUEE 10205 y 10317-. La presencia de TSHT y TSA D permiten datar la formación de estos contextos en torno a mediados del s. v d. C., momento en el que el edificio palacial estaría ya abandonado como tal y sometido a un proceso de expolio de su material constructivo. Estas cerámicas aparecen acompañadas de producciones de cerámica común con formas de clara tradición tardorromana, si bien detectamos ya la presencia de los acabados engobados del grupo A1 1 y la aparición de las ollas con perfil en "s".

Hemos documentado un segundo momento de hábitat tardoantiguo -Fase 2- a partir del estudio de los rellenos 10319/10321, 1032426, $10740 \mathrm{y}$ 10784. En este caso contamos ya con abundante presencia de ollas con perfil en "s" muy marcado y con la aparición de piezas elaboradas a mano y a torneta del grupo A10, así como de bases convexas. Destacamos también la ausencia de producciones de sigillata en estos contextos. Como hemos indicado, las bases convexas aparecen asociadas a un momento avanzado de época tardoantigua; en nuestro caso podemos ofrecer una datación de radiocarbono (600-660 d. C.) para la primera presencia de este tipo de base en el yacimiento de Santa María de Abajo de Carranque ${ }^{27}$. En este sentido queremos destacar que la presencia de la tumba 1/1996 sobre el relleno 10319/10321 indica que este hábitat tardoantiguo sería, al menos parcialmente, amortizado por la necrópolis.

El tercer momento de ocupación tardoantigua atestiguado se corresponde con la instalación de una amplia necrópolis -Fase 3- que parece surgir en torno a un edificio de culto y que ha sido objeto de un reciente estudio ${ }^{28}$. En el presente trabajo, hemos analizado los materiales del relleno de la tumba 154 -UE 10288- y del ajuar de la tumba 1 -UE 10226-. En ambos casos destaca la presencia de bases convexas junto a ollas con marcado perfil en "s" en el caso de la UE 10288. La datación radiocarbónica del último de los individuos inhumados en la tumba 154 (600-660 d. C.) nos permite otorgar

26 Como se ha apuntado líneas arriba, hemos podido documentar a través de relación estratigráfica en el segundo momento de la fase 2 una sucesión de fosas -UUEE 10353 y 10355 - sin que los materiales del relleno de las mismas -10319/10321 y 10324 respectivamente- permitan establecer una diferencia cronológica entre ellas. A tenor del estudio cerámico realizado, podemos inferir que la colmatación de estas fosas parece ser posterior a la de las fosas adscritas al primer momento de la Fase 2 -UUeE 10205 y 10317 -.

27 Cf. n. 24.

28 Cf. García-Entero et al., op. cit. n. 3. 
esta cronología, con la prudencia con la que deben ser tomadas las fechas radiocarbónicas, al relleno UE 10288. La continuidad de los trabajos arqueológicos más allá de los límites impuestos por la adecuación para la visita de este sector del Parque Arqueológico permitirán avanzar en el conocimiento del hábitat tardoantiguo instalado en el yacimiento de Santa María de Abajo de Carranque.

\section{Bibliografía}

Alba, M. y Feijoo, S. (2003): "Pautas evolutivas de la cerámica común de Mérida en épocas visigoda y emiral". En Caballero, L.; Mateos, P. y Retuerce, M. (eds.): Cerámicas tardorromanas y altomedievales en la Peninsula Ibérica. Ruptura y continuidad (II Simposio de Arqueología. Mérida, 2001). Madrid: csic, pp. 483-504.

Amorós, V. (2013): "Tendencias tecnológicas de la cerámica altomedieval del Tolmo de Minateda", Mansio, 1, pp. 7-25.

Amorós, V.; Cañavate, V.; Gutiérrez Lloret, S. y Sarabia, J. (2012): "Cerámica altomedieval en el Tolmo de Minateda (Hellín, Albacete, España)". En Gelichi, S. (a cura di): Atti IX Congresso Internazionale sulla Ceramica Medievale nel Mediterraneo (Venezia, 2009). Firenze: All'Insegna del Giglio, pp. 246-257.

Aranda, R. (2013): “Una aportación al conocimiento de las producciones cerámicas de época visigoda. El conjunto cerámico de la Parcela R3 de la Vega Baja de Toledo", Espacio Tiempo y Forma, Serie I. Prehistoria y Arqueología, nueva época 6, pp. 377-446.

Aranda, R. (2014): "Cerámica de época visigoda: una historia de la investigación”, AnMurcia 30, pp. 7195.

Ariño, E. y Dahí, S. (2012): "La cerámica de los yacimientos rurales de la provincia de Salamanca (España) entre la Antigüedad Tardía y la alta Edad Media (350-700)", Archeologia medievale, 39, pp. 371-383.

Ariño, E.; SuÁrez, M. y Sánchez Santos, J. M. (2015): "La cerámica del yacimiento de época visigoda de El Cuquero (Villanueva del Conde, Salamanca, España): estudio arqueométrico", Salduie 15, pp. 181-196.

Baldini, I. (2002): La domus tardoantica. Forme e rappresentazioni dello spazio domestico nelle città del Mediterraneo. Bologna: Uрв.
Balmelle, C. (2001): Les demeures aristocratiques d'Aquitaine. Société et culture de l'Antiquité tardive dans le Sud-Ouest de la Gaule. Aquitania, Suppl., 10. Bordeaux-Paris.

Barragán, M. ${ }^{a}$ C. (2012): "Un conjunto de cerámica tardoantigua procedente de la Atalaya de la Moranilla (Écija, Sevilla)", Romula, 11, pp. 249-272.

Barroso, R. y Morín de Pablos, J. (coords.) (2007): Excavaciones arqueológicas en Azután (Toledo). Un modelo de evolución en el poblamiento entre los periodos visigodo y emiral. Madrid: MArqAudema.

Caballero, L. y Moreno Martín, F. J. (2013): "Balatalmelc, Santa María de Melque. Un monasterio del siglo viII en territorio toledano". En Ballestín, X. y Pastor, E. (eds.): Lo que vino de Oriente. Horizontes, praxis y dimensión material de los sistemas de dominación fiscal en Al-Andalus (ss. VII-IX). BAR, 2525. Oxford: Archaeopress, pp. 182-204.

Carmona, S. (1998): Mundo funerario rural en la Andalucía tardoantigua y de época visigoda. La necrópolis de El Ruedo (Almedinilla, Córdoba). Córdoba. Diputación de Córdoba.

Chavarría, A.; Arce, J. y Brogiolo, G. P. (eds.) (2006): Villas tardoantiguas en el Mediterráneo occidental. Anejos de Archivo Español de Arqueología, xxxix. Madrid: Csic.

Dahí, S. (2012): Contextos cerámicos de la Antigüedad Tardía y Alta Edad Media (siglos IV-VIII d. C.) en los asentamientos rurales de la Lusitania septentrional (provincia de Salamanca, España). BAR, Intern. Ser., 2401. Oxford: Archaeopress.

Ellis, S. P. (1984): An Archaeological Study of Urban Domestic Housing on the Mediterranean AD 400-700. Oxford.

Ellis, S. P. (1991): "Power, Architecture and Decor: How the Late Roman Aristocrat appeared to his guests”. En GazDa, E. K. (ed.): Roman Art in private sphere. Michigan, pp. 117-134.

Fernández FernándeZ, A. (2014): El comercio tardoantiguo (ss. IV-VI) en el noroeste peninsular a través del registro cerámico de la Ría de Vigo. Oxford: Archaeopress.

Fernández Ochoa, C.; García-Entero, V. y Peña, Y. (2012): "Evidencias del edificio termal de la villa de Carranque (Toledo) en el marco de su evolución arquitectónica". En Fernández IbáŃEZ, C. y Bohigas, R. (eds.): In Durii Regione Romanitas. Estudios sobre la romanización del Valle del Duero en Homenaje a J. Cortés Álvarez de Miranda. Santander, pp. 389-396. 
FlöRCHINGER, A. (1998): Romanische Gräber in Südspanien. Beigaben- und Bestattungssitte in westgotenzeitlichen Kirchennekropolen. Marburger Studien zur Vor- und Frühgeschichte, 19. Leidorf: Rahden/ Westf.

Fuentes, A. (1989): La necrópolis tardorromana de Albalate de las Nogueras (Cuenca) y el problema de las denominadas "necrópolis del Duero". Cuenca: Diput. Prov. de Cuenca.

Gallego García, M.a M. (2010): "La secuencia cerámica de época visigoda de la Vega Baja. Una primera aproximación”. En GARCía, A. (coord.): Espacios urbanos en el occidente mediterráneo (ss. VI-VIII). Toletum Visogodo. Toledo, pp. 315-326.

García-Entero, V.; Fernández Ochoa, C.; Peña, Y. y Zarco, E. (2014): "La evolución arquitectónica del edificio palacial de Carranque (Toledo, España). Primeros avances". En Pensabene, P. y Sfameni, C. (a cura di): La villa restaurata e i nuovi studi sull'edilizia residenziale tardoantica. Atti Convegno Internazionale del CISEM (Piazza Armerina, 2012). Bari: Edipuglia, pp. 477-486.

García-Entero, V.; Peña, Y.; Zarco, E. y Aranda, R. (2017): "Contextos cerámicos emirales del yacimiento de Carranque (Toledo)", Archivo Español de Arqueología, 90, pp. 97-124.

García-Entero, V. y Vidal, S. (2007): "Marmora from the Roman site of Carranque (Toledo, Spain)", MARMORA. An International Journal for Archaeology, History and Archaeometry of Marbles and Stones, 3, pp. 53-69.

García-Entero, V. y Vidal, S. (2012): "El uso del marmor en el yacimiento de Carranque (Toledo)". En García-Entero, V. (ed.): El marmor en Hispania: explotación, uso y difusión en época romana. Madrid: UNED, pp. 135-153.

Gimeno, H. y Sastre, I. (2009): "Jarritas y recipientes de uso funerario y el culto a los mártires en la Antigüedad tardía”. En Espacios, usos y formas de la epigrafia hispana en época antigua y tardoantigua. Homenaje al Dr. A. U. Stylow. Anejos de Archivo Español de Arqueología, XLVIII. Madrid: Csic, pp. 167-176.

Gómez Laguna, A. J. y Rojas, J. M. (2009): "El yacimiento de la Vega Baja de Toledo. Avance sobre las cerámicas de la fase emiral". En Actas VIII Congreso Internacional de Cerámica medieval (Ciudad Real-Almagro, 2006). Ciudad Real, t. II, pp. 785-804.

Gutiérrez Lloret, S. (1996): La cora de Tudmir: de la Antigüedad tardía al mundo islámico: poblamiento y cultura material. Coll. Casa de Velázquez, 57. Madrid.

(C) Universidad de Salamanca
Gutiérrez Lloret, S.; Gamo, B. y Amorós, V. (2003): "Los contextos cerámicos altomedievales del Tolmo de Minateda y la cerámica altomedieval en el Sudeste de la Península Ibérica”. En Caballero, L.; Mateos, P. y Retuerce, M. (eds.): Cerámicas tardorromanas y altomedievales en la Peninsula Ibérica. Ruptura y continuidad. Anejos de Archivo Español de Arqueología, xxviII. Madrid: CSIC, pp. 119-168.

Hayes, J. W. (1972): Late Roman Pottery. A catalogue of Roman Fine Wares. London: BSR.

Hayes, J. W. (1980): A Supplement to Late Roman Pottery. London: BSR.

IzQuiERdo, R. (1977): "Ensayo de una sistematización tipológica de la cerámica de necrópolis de época visigoda”, RABM, LXXX (4), pp. 837-865.

Juan Tovar, L. C. (2000): "La terra sigillata de Quintanilla de la Cueza". En García Guinea, M. A. (coord.): La villa romana de Quintanilla de la Cueza (Palencia). Memoria de las excavaciones 1970-1981. Salamanca: JcyL, pp.45-122.

larrén, H.; Blanco, J. F.; Villanueva, O.; Caballero, J.; Domínguez, A.; Nuño, J.; Sanz, F. J.; Marcos, G. J.; Martín, M. A. y Misiego, J. (2003): "Ensayo de sistematización de la cerámica tardoantigua en la Cuenca del Duero". En Caballero, L.; Mateos, P. y Retuerce, M. (eds.): Cerámicas tardorromanas y altomedievales en la Peninsula Ibérica. Ruptura y continuidad. Anejos de Archivo Español de Arqueología, XXVIII. Madrid: Csic, pp. 273-306.

Lavin, I. (1962): "The House of the Lord. Aspects of the Role of Palace-Triclinia in the Architecture of Late Antiquity and the Early Middle Ages", The Art Bulletin, 44, pp. 1-27.

López LaNCHA, R. (2001): “Inscripción árabe en la basílica”. En AA. vv.: Carranque. Centro de Hispania romana. Guadalajara: AACHE eds., pp. 137-138.

Mar, R. y Verde, G. (2008): "Las villas tardoantiguas: cuestiones de tipología arquitectónica”. En FernáNdez Ochoa C.; García-Entero V. y Gil Sendino, F. (eds.): Las villae tardorromanas en el Occidente del Imperio: Arquitectura y función (IV Coloquio Internacional de Arqueología en Gijón, 2006). Gijón: Trea, pp. 49-83.

Matthews, W. (1975): Western Aristocracies and Imperial Court, $A D$ 364-425. Oxford: Clarendon Press.

Olmo, L. y Castro, M. (2008): "La cerámica de época visigoda de Recópolis: apuntes tipológicos desde un análisis estratigráfico". En Olmo, L. (ed.): Recópolis y la ciudad en época visigoda. Zona Arqueológica, 9. Madrid: MAR, pp. 88-97. 
172 V. García, Y. Peña, E. Zarco y R. Aranda / Contextos cerámicos tardoantiguos procedentes del edificio palacial...

Paz Peralta, J. A. (1991): Cerámica de mesa romana de los siglos III al vI d.C. en la provincia de Zaragoza. Zaragoza.

Paz Peralta, J. A. (2008): "Las producciones de terra sigillata hispánica intermedia y tardía”. En Bernal, D. y Ribera i Lacomba, A. (eds.): Cerámicas hispanorromanas. Un estado de la cuestión. Cádiz: UCA, pp. 497-439.

Pensabene, P. y Sfameni, C. (a cura di) (2014): La villa restaurata e i nuovi studi sull'edilizia residenzial e tardoantica. Atti del Convegno Internazionale del CISEM (Piazza Armerina, 2012). Bari: Edipuglia.

Reynolds, P. (1993): Settlement and Pottery in the Vinalopo Valley (Alicante, Spain), AD 400-700. BAR Intern. Ser., 588. Oxford: Archaeopress.

Rodríguez Morales, J. y Viguera, M. ${ }^{a}$ J. (2014): “La columna inscrita de Santa María de Abajo-Carranque. Nueva lectura". En Actas décimas Jornadas de Patrimonio Arqueológico en la Comunidad de Madrid. Madrid, p. 373.

Román, J. M. (2007): "Jarritos funerarios en las necrópolis rurales tardoantiguas (s. IV-VIII d. C.) de la provincia de Granada", CVDAS: Revista de Arqueología e Historia, 3-4, pp. 103-118.

Sfameni, C. (2006): Ville residenziali nell'Italia tardoantica. Bari: Edipuglia.

Strato (2013a): "Canto Blanco". En Quirós, J. A. (coord.): El poblamiento rural de época visigoda en Hispania: arqueología del campesinado en el interior peninsular. Bilbao: upv, pp. 67-84.

Strato (2013b): "Ladera de los Prados". En Quirós, J. A. (coord.): El poblamiento rural de época visigoda en Hispania: arqueología del campesinado en el interior peninsular. Bilbao: Upv, pp. 85-100.

Strato (2013c): "Navamboal”. En Quirós, J. A. (coord.): El poblamiento rural de época visigoda en Hispania: arqueología del campesinado en el interior peninsular. Bilbao: upv, pp. 116-133.

Strato (2013d): "Mata del Palomar". En Quirós, J. A. (coord.): El poblamiento rural de época visigoda en Hispania: arqueología del campesinado en el interior peninsular. Bilbao: upv, pp. 134-154.

Vigil-Escalera, A. (1999): "Evolución de los morfotipos de cerámica común de un asentamiento rural visigodo de la meseta (Gózquez de Arriba, San Martín de la Vega, Madrid)", Revista Arqueohispania, 0, s/p.

Vigil-Escalera, A. (2003): "Cerámicas tardorromanas y altomedievales de Madrid". En Caballero, L.; Mateos, P. y Retuerce, M. (eds.): Cerámicas tardorromanas y altomedievales en la Peninsula Ibérica. Ruptura y continuidad. Madrid: Csic, pp. 371-387.

Vigil-Escalera, A. (2007a): "Granjas y aldeas tardoantiguas y altomedievales de la Meseta. Configuración espacial, socioeconómica y política de un territorio rural al norte de Toledo (ss. v-x d. C.)", Archivo Español de Arqueología, 80, pp. 239-284.

Vigil-Escalera, A. (2007b): "Algunas observaciones sobre las cerámicas 'de época visigoda' (ss. V-IX d. C.) de la región de Madrid”. En Malpica, A. y CarvaJAL, J. C. (eds.): Estudios de cerámica tardorromana y altomedieval. Salobreña: Alhulia, 357-382.

Vigil-Escalera, A. (2009a): "El poblamiento rural del sur de Madrid y las arquitecturas del siglo vir". En Caballero, L.; Mateos, P. y Utrero, M. a Á. (coords.): El siglo VII frente al siglo VII. Arquitectura. Visigodos y omeyas, 4. Madrid: CsIC, pp. 205-230.

Vigil-Escalera, A. (2009b): "Sepulturas, huertos y radiocarbono (siglos viII-XIII d. C.): El proceso de islamización en el medio rural del centro peninsular y otras cuestiones", Studia Historica. Historia Medieval, 27, pp. 97-118.

Vigil-EsCALERA, A. (2015): Los primeros paisajes altomedievales en el interior de Hispania. Registros campesinos del siglo quinto d. C. Documentos de Arqueología Medieval, 7. Bilbao: upv.

VIÑas, C. y PAZ, R. (1951-1963): Relaciones de los pueblos de España hechas por iniciativa de Felipe II. Reino de Toledo. Madrid: csic.

Wilson, R. J. A. (2011): "The fourth-century villa at Piazza Armerina (Sicily) in its wider imperial context: a review of some aspects of recent research". En BüLOw, G. y Zaвehlicky, H. (eds.): Ruckneudorf und Gamzigrad. Spätantike Paläste und Grossvillenim Donau-Balkan-Raum. Akten des Internationalen Kolloquiums in Bruckneudorf (Wien, 2008). Bonn: Römisch-Germanische Kommission, pp. 55-87. 